\title{
Bifunctional CoFeO/ZnO Core/Shell Nanoparticles for Magnetic Fluid Hyperthermia With Controlled Optical Response
}

Gabriel Lavorato, Enio Lima, Jr., Marcelo Vasquez Mansilla, Horacio E. Troiani, Roberto Daniel Zysler, and Elin Winkler

J. Phys. Chem. C, Just Accepted Manuscript • DOI: 10.1021/acs.jpcc.7b11115 • Publication Date (Web): 23 Jan 2018

Downloaded from http://pubs.acs.org on January 26, 2018

\section{Just Accepted}

"Just Accepted" manuscripts have been peer-reviewed and accepted for publication. They are posted online prior to technical editing, formatting for publication and author proofing. The American Chemical Society provides "Just Accepted" as a free service to the research community to expedite the dissemination of scientific material as soon as possible after acceptance. "Just Accepted" manuscripts appear in full in PDF format accompanied by an HTML abstract. "Just Accepted" manuscripts have been fully peer reviewed, but should not be considered the official version of record. They are accessible to all readers and citable by the Digital Object Identifier (DOI®). "Just Accepted" is an optional service offered to authors. Therefore, the "Just Accepted" Web site may not include all articles that will be published in the journal. After a manuscript is technically edited and formatted, it will be removed from the "Just Accepted" Web site and published as an ASAP article. Note that technical editing may introduce minor changes to the manuscript text and/or graphics which could affect content, and all legal disclaimers and ethical guidelines that apply to the journal pertain. ACS cannot be held responsible for errors or consequences arising from the use of information contained in these "Just Accepted" manuscripts. 


\title{
Bifunctional $\mathrm{CoFe}_{2} \mathrm{O}_{4} / \mathrm{ZnO}$ Core/Shell Nanoparticles for Magnetic Fluid Hyperthermia with Controlled Optical Response
}

\author{
Gabriel Lavorato ${ }^{1,2, *}$, Enio Lima $\mathrm{Jr}^{1}$, Marcelo Vasquez Mansilla ${ }^{1}$, Horacio Troiani ${ }^{1}$, \\ Roberto Zysler ${ }^{1}$, Elin Winkler ${ }^{1, *}$
}

1 Centro Atómico Bariloche, CNEA-CONICET, Av. Bustillo 9500, Bariloche, Río Negro, Argentina

2 Centro Brasileiro de Pesquisas Fisicas, Rua Dr. Xavier Sigaud 150, Rio de Janeiro, Brazil

*E-mail: gclavorato@gmail.com; winkler@cab.cnea.gov.ar

\begin{abstract}
Conjugation of optical and magnetic responses in a unique system at the nanoscale emerges as a powerful tool for several applications. Here, we fabricated bifunctional $\mathrm{CoFe}_{2} \mathrm{O}_{4}-$ core/ZnO-shell nanoparticles with simultaneous photoluminescence in the visible range and ac magnetic losses suitable for hyperthermia. The structural characterization confirms that the system is formed by $\mathrm{a} \approx 7 \mathrm{~nm} \mathrm{CoFe}_{2} \mathrm{O}_{4}$ core encapsulated in a $\approx 1.5 \mathrm{~nm}$-thick semiconducting $\mathrm{ZnO}$ shell. As expected from its high anisotropy, the magnetic losses in an ac magnetic field are dominated by the Brown relaxation mechanism. The ac magnetic response of the core/shell system can be accurately predicted by the linear response theory and differs from that one of bare $\mathrm{CoFe}_{2} \mathrm{O}_{4}$ nanoparticles as a consequence of changes in the viscous relaxation process due to the effect of the magnetostatic interactions. Concerning the optical properties, by comparing core/shell $\mathrm{CoFe}_{2} \mathrm{O}_{4} / \mathrm{ZnO}$ and single-phase $\mathrm{ZnO}$
\end{abstract}


nanoparticles, we found that the former exhibit a broader optical absorption and photoluminescence, both shifted to the visible range, indicating that the optical properties are closely associated to the shell-morphology of $\mathrm{ZnO}$. Being focused on bifunctional nanoparticles with an optical response in the visible range and a tunable hyperthermia output, our results can help to address current open questions on magnetic fluid hyperthermia.

\section{INTRODUCTION}

Research on magnetic nanoparticles (NPs) for biomedical applications has been continuously growing in fields such as magnetic fluid hyperthermia (MFH), drug delivery, magnetic separation of biomolecules and contrast agents for magnetic resonance imaging (MRI) ${ }^{1}$. MFH consists in destroying tumor cells by the localized heat generation of a colloid of magnetic NPs exposed to a biologically relevant radiofrequency magnetic field and is currently one of the most promising strategies to supplement traditional oncological therapies $^{2-5}$. In parallel, the optical labeling of MFH-suitable NPs would allow for their detection through fluorescence imaging and could provide a powerful tool to evaluate the NPs in biological environments ${ }^{6,7}$. In this way, bifunctional core/shell NPs with both optical and magnetic response are of great interest in several biomedical areas, to be used as markers and magnetic drivers ${ }^{8,9}$. However, in our opinion, the design of multifunctional NPs oriented to MFH has not been fully explored.

The successful applications of NPs require the ability to tune their properties. Besides the control of the NPs' size and composition, their properties are governed by their shape, morphology, interactions and long-range order, which remain an important research goal to be addressed. In this way, we expect distinct magnetic and optical properties for bifunctional 
core/shell structures when compared to the respective properties of isolated single-phase NPs.

Enormous efforts were made, and continue to be made, in order to increase the inductive heating efficiency of the NPs and to reduce the minimum dose required to achieve a therapeutic effect ${ }^{10-14}$. The inductive heating efficiency of the NPs, or their ac magnetic losses, is strongly dependent on the morphological, magnetic and rheological properties of the system, as well as on the frequency and amplitude of the external ac magnetic field. The magnetic losses depend on the dephasing between the external field and the relaxation of the magnetic moment, which occurs in two ways ${ }^{15}$ : a magnetic relaxation associated with Néel relaxation time, depending on the magnetic anisotropy and magnetic volume, and a viscous relaxation, associated with the Brown relaxation time and depending on the viscosity of the medium and the hydrodynamic diameter. However, after such strong progress, the future of MFH may lay on engineering the NPs to achieve an optimal concentration in the tumor after a systemic injection ${ }^{16}$, without surpassing toxicity limits. The precise dose incorporated by biological systems such as organs, tissues or cells is difficult to evaluate, and the detection and quantification of the particles are still important challenges ${ }^{17}$. To overcome this difficulty, MRI can be used to detect the $\mathrm{NPs}^{1,18}$, but the ideal properties of the material for MFH do not necessarily meet the requirements for a MRI contrast agent ${ }^{1,19,20}$. It is known that the local concentration of NPs can be strongly modified in different environments (water, viscous media, on membranes, inside cells) or upon cellular uptake, leading to marked changes in the heating efficiency ${ }^{21,22}$ and in the cytotoxicity of the $\mathrm{NPs}^{23}$. At the same time, the effects of the heat generated and transferred at a cellular and molecular level and the associated cell death pathways are still under debate ${ }^{24-26}$, including new therapies based on non-apoptotic cell death mechanisms triggered by the local heat generation in $\mathrm{MFH}$ 
experiments $^{27}$. Therefore, the development of bifunctional systems that may act as optical markers is worthwhile to the future development of MFH.

Due to their tunable photoluminescence in the visible range and larger photostability compared to organic dyes, plasmonic NPs and quantum dots have been proposed for biological markers in the last years ${ }^{28-30}$ and, for example, semiconducting oxides such as $\mathrm{ZnO}$ or $\mathrm{TiO}_{2}$ can be used as inorganic probes for optical labelling taking profit from their good biocompatibility ${ }^{31-33}$. Multicomponent NPs have been recently proposed as well, aiming at combining the properties of distinct materials ${ }^{34}$, to take advantage of the properties emerging from the interactions between their components ${ }^{35,36}$ or to protect/functionalize the core $^{37,38}$. In this context, some recent studies have been focused on the development of core/shell multicomponent NPs that combine both magnetic and optical properties ${ }^{39-41}$. For instance, Cho et al. employed $\mathrm{Fe}_{3} \mathrm{O}_{4} / \mathrm{ZnO}$ core/shell NPs to deliver antigens in a dendriticbased approach against cancer, acting simultaneously as a delivery and labeling agent that can be detected by confocal microscopy and flux cytometry ${ }^{42}$, and $\mathrm{CoFe}_{2} \mathrm{O}_{4} / \mathrm{ZnO}$ core/shell NPs were also proposed to act simultaneously as a fluorescence optical imaging and a MRI contrast agent ${ }^{43}$.

The cobalt ferrite $\left(\mathrm{CoFe}_{2} \mathrm{O}_{4}\right)$, with a similar saturation magnetization compared to magnetite but a much higher magnetocrystalline anisotropy, has been widely studied in hyperthermia ${ }^{15,44-47}$ since it provides a model-system to study the effects of the anisotropy on the heating capability ${ }^{15,46}$. While important concerns have been raised regarding the toxicity effects of Co ions in physiological environments ${ }^{48,49}$, the passivation of the NPs' surface with a biocompatible inorganic shell could provide a potential solution ${ }^{50}$. Regarding $\mathrm{ZnO}$, it is a biocompatible low-cost semiconducting oxide that has been extensively applied 
in optics, optoelectronics, catalysis and piezoelectricity, promoted by the versatility of fabricating it in many different nanostructured forms $\mathrm{s}^{51,52}$.

The design of novel multifunctional NP-based systems to address specific biomedical issues usually requires the development of complex materials and incorporating imaging probes in a single compact bifunctional nanoparticle is a key aspect of multifunctional nanosystems ${ }^{6}$. In this aim, here we fabricated and studied a core/shell nanoparticle system formed by a magnetic $\mathrm{CoFe}_{2} \mathrm{O}_{4}$ core and a photoluminescent $\mathrm{ZnO}$ shell. We analyzed the influence of the structure and morphology of $\mathrm{CoFe}_{2} \mathrm{O}_{4} / \mathrm{ZnO}$ core/shell NPs on the magnetic properties, on the hyperthermia output and on the optical response.

\section{EXPERIMENTAL}

Single-phase $\mathrm{CoFe}_{2} \mathrm{O}_{4}$ and $\mathrm{CoFe}_{2} \mathrm{O}_{4} / \mathrm{ZnO}$ core/shell NPs were obtained by the heat-up method $^{53}$. The synthesis route is based on the decomposition of organometallic compounds at high temperature assisted by surfactants in an organic solvent ${ }^{54}$ and core/shell samples can be obtained by a seed-mediated process ${ }^{55,56}$. To fabricate $\mathrm{CoFe}_{2} \mathrm{O}_{4} \mathrm{NPs}, 1 \mathrm{mmol}$ of $\mathrm{Co}(\mathrm{II})$ acetylacetonate $\left(\mathrm{Co}(\mathrm{acac})_{2}\right), 2 \mathrm{mmol}$ of $\mathrm{Fe}(\mathrm{III})$ acetylacetonate $\left(\mathrm{Fe}(\mathrm{acac})_{3}\right)$ were mixed with $18 \mathrm{mmol}$ of Oleic Acid, $18 \mathrm{mmol}$ of Oleylamine, $2 \mathrm{mmol}$ of 1,2-octanediol and $380 \mathrm{mmol}$ of diphenyl ether. Once the excess of humidity was removed by keeping a constant temperature of $120^{\circ} \mathrm{C}$ for $20 \mathrm{~min}$, the mixture was magnetically stirred and heated at a constant rate of 8 ${ }^{\circ} \mathrm{C} / \mathrm{min}$ up to $200{ }^{\circ} \mathrm{C}$, temperature that was kept for $10 \mathrm{~min}$. Then the mixture was heated again at a rate of $10^{\circ} \mathrm{C} / \min$ up to the reflux temperature $\left(260^{\circ} \mathrm{C}\right)$, which was kept for another $120 \mathrm{~min}$. After cooling the sample down to room temperature, a small fraction $(10 \mathrm{~mL})$ of liquid was extracted in order to analyze bare $\mathrm{CoFe}_{2} \mathrm{O}_{4}$ NPs. Afterwards, in order to overgrow 
a $\mathrm{ZnO}$ shell on the ferrite core, $2 \mathrm{mmol}$ of $\mathrm{Zn}(\mathrm{II})$ acetylacetonate $(\mathrm{Zn}(\mathrm{acac}) 2)$ were added to the preparation together with $3 \mathrm{mmol}$ of Oleic Acid, $3 \mathrm{mmol}$ of Oleylamine, $1 \mathrm{mmol}$ of 1,2octanediol and $129 \mathrm{mmol}$ of diphenyl ether. The mixture was then heated to the reflux temperature $\left(260^{\circ} \mathrm{C}\right)$ at a constant rate of $10^{\circ} \mathrm{C} / \mathrm{min}$ and was kept at that temperature for another $120 \mathrm{~min}$. Once the solution was cooled to room temperature, the NPs were washed several times with an ethanol and toluene 8:1 mixture and precipitated by using a permanent magnet. This process was carried out for both $\mathrm{CoFe}_{2} \mathrm{O}_{4}$ and $\mathrm{CoFe}_{2} \mathrm{O}_{4} / \mathrm{ZnO}$ core/shell NPs, ensuring that only magnetic particles were collected and that residual free $\mathrm{ZnO}$, if present, was discarded. Finally, the samples were redispersed in toluene and kept at $-20{ }^{\circ} \mathrm{C}$. In order to perform the structural characterization, a portion of each sample was dried by evaporating the toluene.

The residual organic mass from the synthesis was evaluated through a thermogravimetric analysis (TGA) in a Shimadzu DTG-60H equipment by heating dried fractions of the samples up to $500{ }^{\circ} \mathrm{C}$ at a fixed heating rate of $5^{\circ} \mathrm{C} / \mathrm{min}$ in $\mathrm{Ar}$ flux $(100 \mathrm{~mL} / \mathrm{min}$.).

The crystalline structure and crystallite size were studied by powder x-ray diffraction (XRD) experiments that were conducted in a PANalytical Empyrean instrument ( $\mathrm{Cu}-\mathrm{K} \alpha$ radiation) in the $2 \theta$ range $20-80^{\circ}$ with a step size of $0.02^{\circ}$. Rietveld analyses were performed by using the Fullprof software ${ }^{57}$ and were employed to estimate the mean crystallite size of each phase. The morphology and particle size were evaluated in a Philips CM200 transmission electron microscope (TEM, Ultra-Twin lens, operating at $200 \mathrm{kV}$ ) by measuring 250 particles of each sample from bright-field images; high-resolution TEM images were obtained in a JEOL 2100F microscope. TEM specimens were prepared by dispersing the dry powder in chloroform and dropping the suspension on a carbon-covered copper grid. 
Dynamic light scattering (DLS) experiments were performed in a Malvern Nano ZS90 apparatus at room temperature with a measurement angle of $90^{\circ}$ for samples dispersed in toluene and placed in a quartz cuvette. A viscosity of $0.5564 \mathrm{cP}$ and a refractive index of 1.496 were employed for data processing.

In order to conduct the magnetic measurements, the samples dispersed in toluene were transferred to polyethyleneimine (PEI) which keeps the NPs well-dispersed and immobilized during the experiments. DC magnetization measurements were carried out in a SQUID magnetometer (MPMS Quantum Design) equipped with a superconducting coil that produces magnetic fields up to $50 \mathrm{kOe}$. The temperature dependence of the magnetic moment was analyzed by employing the zero-field cooled/field-cooled (ZFC/FC) and thermoremanent (TRM) conventional protocols with an applied field of 50 Oe. Hysteresis loops were obtained at $5 \mathrm{~K}$ by applying magnetic fields up to $50 \mathrm{kOe}$ and room temperature curves were measured by applying magnetic fields up to $10 \mathrm{kOe}$. The heating efficiency of the NPs was assessed by analyzing the field-dependence of the magnetization during the application of a radiofrequency magnetic field in an $\mathrm{AC}$ hysteresis loop tracer. $\mathrm{M}$ vs $\mathrm{H}$ loops were recorded for NPs dispersed in toluene (total volume of $\approx 0.5 \mathrm{~mL}$ and concentration $\approx 1.5 \mathrm{mgNPs} / \mathrm{mL}$ ) by an inductive method during the application of an alternating magnetic field with amplitude of $80 \mathrm{Oe}$ and frequency of $85 \mathrm{kHz}$.

UV-visible spectroscopy experiments were conducted in a Perkin Elmer Lambda-35 spectrometer. Room temperature spectra of NPs dispersed in hexane were acquired for a wavelength in the range $250-700 \mathrm{~nm}$. Photoluminescence spectra were obtained in a Horiba FluoroMax-4P spectrofluorometer. The experiments were carried out for NPs dispersed in hexane at room temperature in the range 350-700 $\mathrm{nm}$ with a fixed excitation wavelength of 
$\lambda=350 \mathrm{~nm}$. In both cases, a quartz cuvette was used as sample-holder and another quartz cuvette with hexane was used as blank.

\section{RESULTS AND DISCUSSION}

\subsection{Structure and morphology}

$\mathrm{CoFe}_{2} \mathrm{O}_{4}$ and $\mathrm{CoFe}_{2} \mathrm{O}_{4} / \mathrm{ZnO}$ core/shell NPs were successfully synthesized by adapting the heat-up method that has demonstrated a remarkable versatility for the fabrication of multicomponent nanostructures. The synthesis procedure allows to control the size of the core by changing the surfactants-to precursors ratio ${ }^{58}$, the heating rate ${ }^{59}$ or, alternatively, by a seed-mediated process ${ }^{60}$. At the same time, the thickness of the shell can be adjusted by controlling the concentration of $\mathrm{Zn}(\mathrm{acac})_{2}$ in the second step of the process ${ }^{39}$.

Figure 1 shows representative TEM micrographs of both samples. The associated size histograms (Figure 1c) were fitted by a lognormal function given by $f(D)=$ $(\sqrt{2 \pi} \sigma D)^{-1} e^{\frac{-\ln ^{2}\left(D / D_{0}\right)}{2 \sigma^{2}}}$ and the obtained results are summarized in table 1 . The mean diameter of the NPs was calculated from the mean value of the lognormal fit $\left\langle D_{N P}\right\rangle=D_{0} e^{\sigma^{2} / 2}$ and is found to be around $7 \mathrm{~nm}$ and $10 \mathrm{~nm}$ for $\mathrm{CoFe}_{2} \mathrm{O}_{4}$ and core/shell NPs, respectively. The size dispersion, given by the standard deviation calculated through $\sigma_{N P}=\left\langle D_{N P}\right\rangle \sqrt{e^{\sigma^{2}}-1}$, increases for the core/shell system, probably due to the increase in the polydispersity during the second step of the synthesis process. High-resolution TEM images allow to distinguish different orientations for the core and shell crystal structures, as shown in Figures 1e-f and in the FFT of selected core and shell areas (inset of Figure 1f). The analysis confirms the 
core/shell morphology and indicates that $\sim 7 \mathrm{~nm}$ cores are encapsulated in a $\sim 1.5 \mathrm{~nm}$-thick shell, in good agreement with the size distribution histograms.

X-ray diffractograms of both samples are reported in Figure 2 and the expected positions for bulk $\mathrm{CoFe}_{2} \mathrm{O}_{4}(\mathrm{a}=8.39 \AA)$ spinel and $\mathrm{ZnO}$ würtzite $(\mathrm{a}=3.25 \AA$ and $\mathrm{c}=5.2 \AA)$ are indicated in the graph. $\mathrm{ZnO}$ is difficult to see in the core/shell sample probably because of the substantial peak broadening due to its reduced size and/or lattice distortion as a consequence of the mismatch between the lattices (expected to be around $25 \%$ ). Nevertheless, the $\mathrm{ZnO}$ shell was taken into account in a more detailed microstructural examination with a Rietveld refinement (full lines in Figure 2), which reflects a mean $\mathrm{ZnO}$ diameter of 3.1(3) nm, contributing with a $\approx 17 \%$ of the total diffracted area. Such $\mathrm{ZnO}$ crystallite size is much lower than the whole shell volume but larger than the shell thickness. Therefore, we can consider that the $\mathrm{ZnO}$ is not a single-crystal but is polycrystalline and formed by multiple small $\mathrm{ZnO}$ grains in close contact, in agreement with HRTEM results shown in Figure 1e. This can be attributed to multiple nucleation points at the core's surface during the second step of the synthesis. In addition, although its quantification is rather complex, some cation interdiffusion between core and shell cannot be discarded, as was pointed out in other works $^{61,62}$.

The Co-ferrite diameter estimated by XRD (and summarized in Table 1) is, within the experimental error, equal to $6 \mathrm{~nm}$ for both samples, implying that the crystallite size of the Co-ferrite is kept unchanged after the second step of the synthesis. Such value is slightly smaller compared to the mean diameter obtained from TEM, suggesting some degree of crystalline disorder in the ferrite. 
Table 1. Summary of the structural characterization for single-phase $\mathrm{CoFe}_{2} \mathrm{O}_{4}$ and core/shell $\mathrm{CoFe}_{2} \mathrm{O}_{4} / \mathrm{ZnO}$ NPs: mean crystallite diameter of $\mathrm{CoFe}_{2} \mathrm{O}_{4}\left(\mathrm{D}_{\mathrm{CFO}}\right)$ and $\mathrm{ZnO}\left(\mathrm{D}_{\mathrm{ZnO}}\right)$ obtained from XRD, mean diameter of the NPs, $\left\langle D_{N P}\right\rangle$, obtained from the lognormal fit of TEM histograms and its standard deviation $\left(\sigma_{N P}\right)$, mean hydrodynamic diameter obtained from the lognormal fit of DLS measurements, $\left\langle D_{H}\right\rangle$, and its standard deviation $\left(\sigma_{D_{H}}\right)$. All values are expressed in $\mathrm{nm}$.

\begin{tabular}{|l|c|c|c|c|c|c|}
\hline \multirow{2}{*}{ Sample } & \multicolumn{2}{|c|}{ XRD } & \multicolumn{2}{c|}{ TEM } & \multicolumn{2}{c|}{ DLS } \\
\cline { 2 - 7 } & $\mathrm{D}_{\mathrm{CFO}}$ & $\mathrm{D} \mathrm{ZnO}$ & $\left\langle D_{N P}\right\rangle$ & $\sigma_{N P}$ & $\left\langle D_{H}\right\rangle$ & $\sigma_{D_{H}}$ \\
\hline $\mathrm{CoFe}_{2} \mathrm{O}_{4}$ & $6.1(5)$ & - & 7.2 & 2.1 & 24.2 & 4.1 \\
\hline $\mathrm{CoFe}_{2} \mathrm{O}_{4} / \mathrm{ZnO}$ & $5.9(4)$ & $3.1(3)$ & 10.0 & 3.2 & 12.8 & 2.5 \\
\hline
\end{tabular}



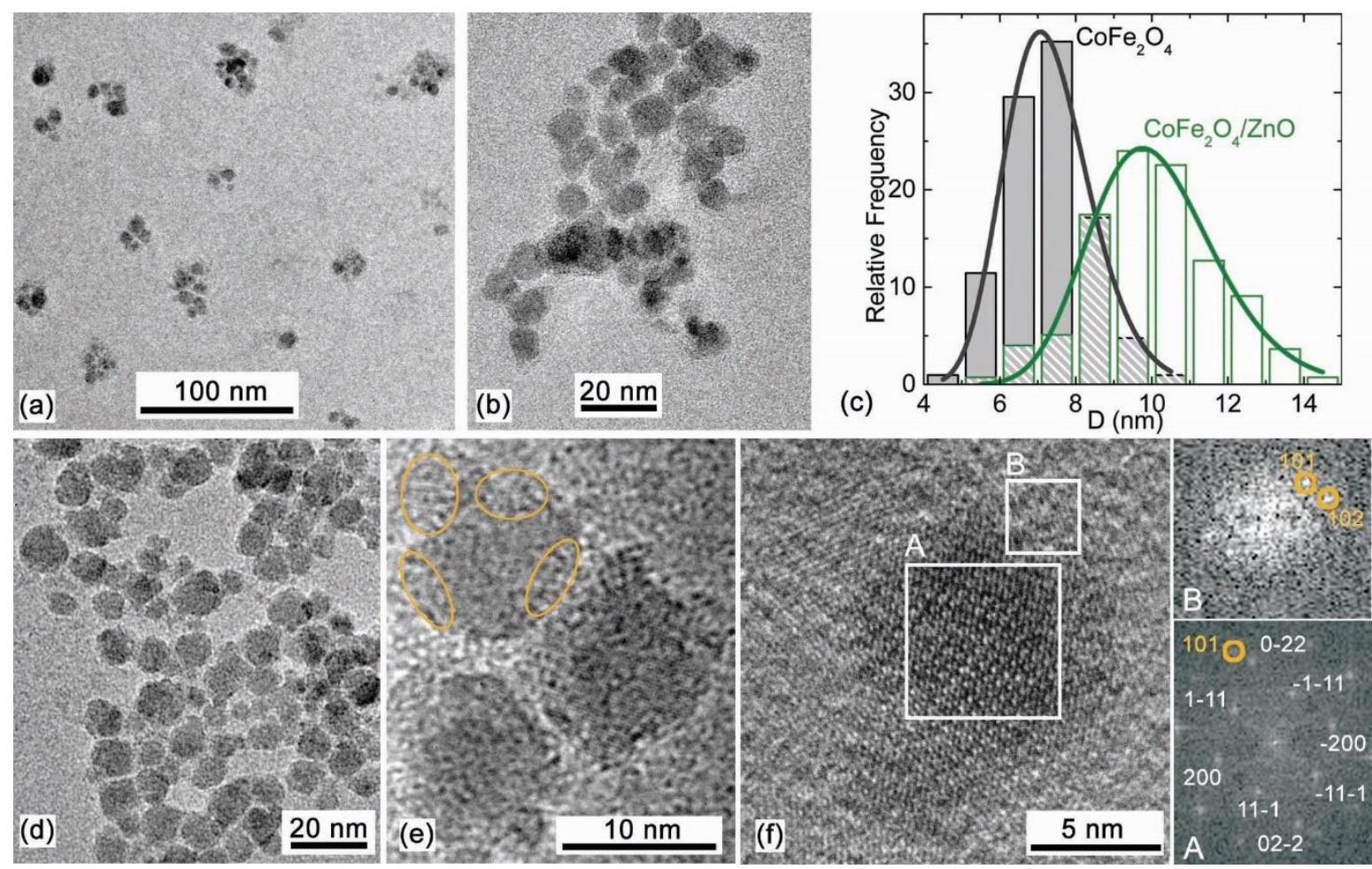

Figure 1: Figure 1a and $1 \mathrm{~b}$ give representative TEM images of $\mathrm{CoFe}_{2} \mathrm{O}_{4} \mathrm{NPs}$. Figure 1c gives the diameter histograms of both samples obtained by measuring the diameter of about 250 particles for each one; solid lines are the fitting with a lognormal distribution. Figures 1d, 1e and 1f show TEM and HRTEM representative images of $\mathrm{CoFe}_{2} \mathrm{O}_{4} / \mathrm{ZnO}$ core/shell NPs, which evidence the core-shell morphology; the insets A and B in Figure 1f indicate the FFT of selected core and shell areas of the image indexed with the planes of $\mathrm{CoFe}_{2} \mathrm{O}_{4}$ and $\mathrm{ZnO}$ (circles). 


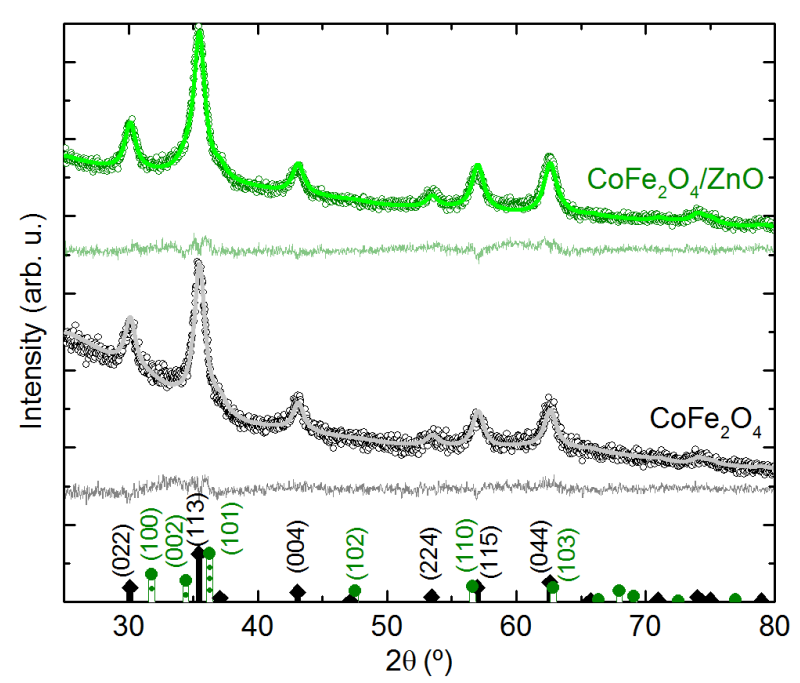

Figure 2. X-ray diffractograms of $\mathrm{CoFe}_{2} \mathrm{O}_{4}$ and $\mathrm{CoFe}_{2} \mathrm{O}_{4} / \mathrm{ZnO}$ NPs. The full lines indicate the Rietveld refinements and their corresponding residuals. The circles and diamonds indicate the position for bulk $\mathrm{ZnO}$ and $\mathrm{CoFe}_{2} \mathrm{O}_{4}$ respectively.

Afterwards, we characterized the colloidal stability of the NPs dispersed in toluene by performing DLS experiments, which are summarized in Figure 3 and table 1. Interestingly, while the mean hydrodynamic diameter $\left\langle D_{H}\right\rangle$ of $\mathrm{CoFe}_{2} \mathrm{O}_{4} / \mathrm{ZnO} \mathrm{NPs}$ results $12.8 \mathrm{~nm}$, in agreement with the size obtained from TEM and XRD plus a thin layer (probably a monolayer) of oleic acid coordinating the $\mathrm{NPs}^{63},\left\langle D_{H}\right\rangle$ of $\mathrm{CoFe}_{2} \mathrm{O}_{4} \mathrm{NPs}$ results significantly larger. This difference suggests the formation of small aggregates of some NPs only for the $\mathrm{CoFe}_{2} \mathrm{O}_{4}$ sample, which is likely to be prevented for core/shell NPs due to the non-magnetic coating. Such feature is also confirmed by TEM images (see Figure 1a) where it is possible to distinguish small aggregates formed by roughly 4-10 NPs. The mean separation between particles is around $1 \mathrm{~nm}$ (the organic layer of an oleic acid monolayer), suggesting that the formation of aggregates is due to magnetostatic interactions rather than due to the coalescence during the synthesis process. In contrast, the non-magnetic $\mathrm{ZnO}$ shell is responsible for an increase in the mean separation distance between magnetic cores 
(schematically shown in the inset of Figure 3), which can be contributing to diminish the interparticle interaction in the core/shell sample. This analysis will be deepened in the next section.

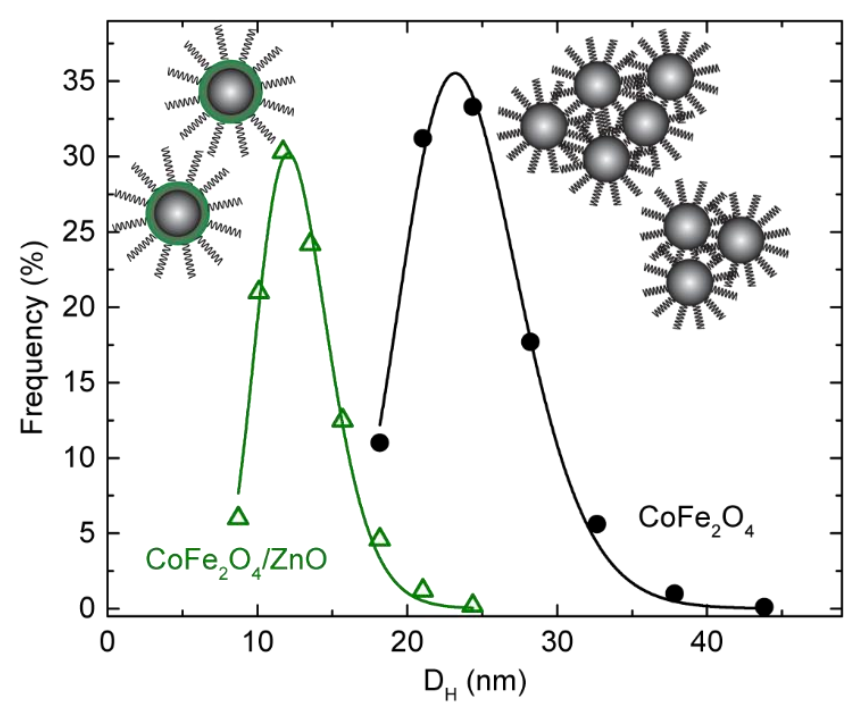

Figure 3. Dynamic light scattering experiments for $\mathrm{CoFe}_{2} \mathrm{O}_{4}$ and $\mathrm{CoFe}_{2} \mathrm{O}_{4} / \mathrm{ZnO}$ NPs. The full lines indicate the fit with a lognormal function. The inset shows schematically the formation of small aggregates for single-phase NPs.

Finally, a thermogravimetric analysis (Figure 4) was performed for each sample to estimate the weight fraction of organic material. For $\mathrm{CoFe}_{2} \mathrm{O}_{4} \mathrm{NPs}$, we obtained about $88 \%$ wt. of organic material, much more than the expected $13 \%$ in the case of an oleic acid monolayer with $1.5 \mathrm{~nm}$ linked to the nanoparticle surface. Also, the core/shell system presents about 65 $\% w t$. of organic material against an expected value of $11 \%$ for the oleic acid monolayer. Thus, in both samples the amount of organic material is larger than the associated to the organic layer linked to the particle. In addition, while bare oleic acid is decomposed at $~ 250$ ${ }^{\circ} \mathrm{C}$, the mass loss associated to the decomposition of the NPs' organic coating is shifted to higher temperatures. In fact, the oleic acid molecules, being embedded at the nanoparticle 
surface, are expected to be stabilized ${ }^{64,65}$. This condition is more evident for core/shell NPs, probably because the smaller amount of organic material in this sample improves the ratio of organic material linked to the particle surface.

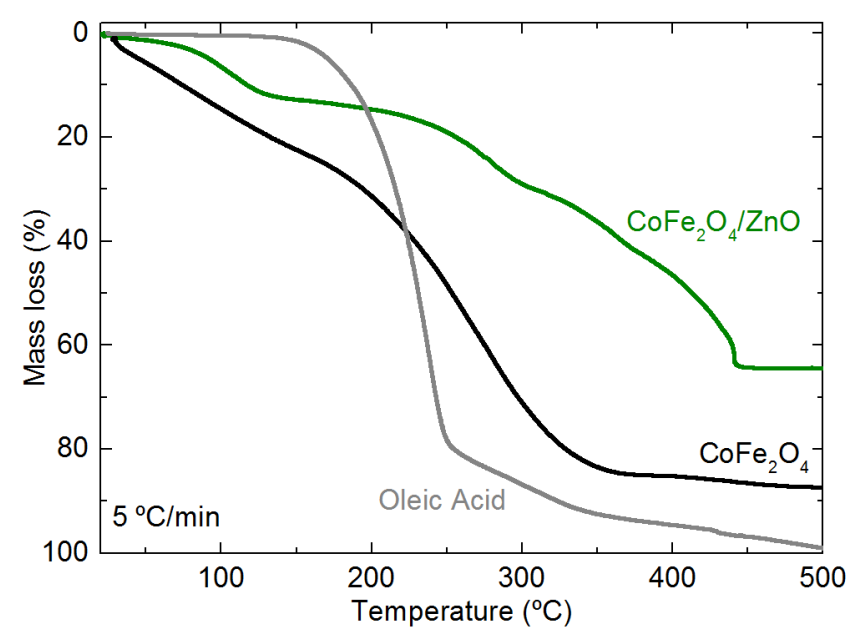

Figure 4. Thermogravimetric analyzes of $\mathrm{CoFe}_{2} \mathrm{O}_{4}$ and $\mathrm{CoFe}_{2} \mathrm{O}_{4} / \mathrm{ZnO}$ NPs in Ar flux. For comparison, the same measurement was performed for pure oleic acid.

From XRD and TEM analyses, the core-shell morphology was described and the sizes of core and shell were obtained. Concomitantly, DLS results point out the effectiveness of the $\mathrm{ZnO}$ shell in avoiding agglomeration of core/shell NPs, which is indeed observed for bare $\mathrm{CoFe}_{2} \mathrm{O}_{4}$. This is likely to be due to a reduction in the dipolar inter-particle interaction for the core/shell system because of the increment in the distance between magnetic dipoles. We notice that the mass loss observed in the thermogravimetric analyses indicates a large amount of organic component in both samples, excluding the possibility that the difference in the hydrodynamic diameters were solely due to the presence of such organic material.

\subsection{Magnetic properties}


Figures $5 \mathrm{a}$ and $5 \mathrm{~b}$ show the thermal dependence of the magnetization for both samples according to the ZFC-FC and TRM protocols, respectively. The shape of the ZFC-FC curves suggests a progressive blocking of the magnetic moments without evidence of significant interparticle interactions. The distributions of blocking temperatures, shown in the insets of each graph, were estimated from $f\left(T_{B}\right)=-\frac{1}{T} \frac{d\left(M_{Z F C}-M_{F C}\right)}{d T}$ and $f\left(T_{B}\right)=-\frac{1}{T} \frac{d M_{T R M}}{d T}$ and were fitted with a lognormal function. The mean value of the fit, $\left\langle T_{B}\right\rangle$, is an indicator of the thermal stability of the system and is slightly larger for core/shell NPs, as given in table 2.
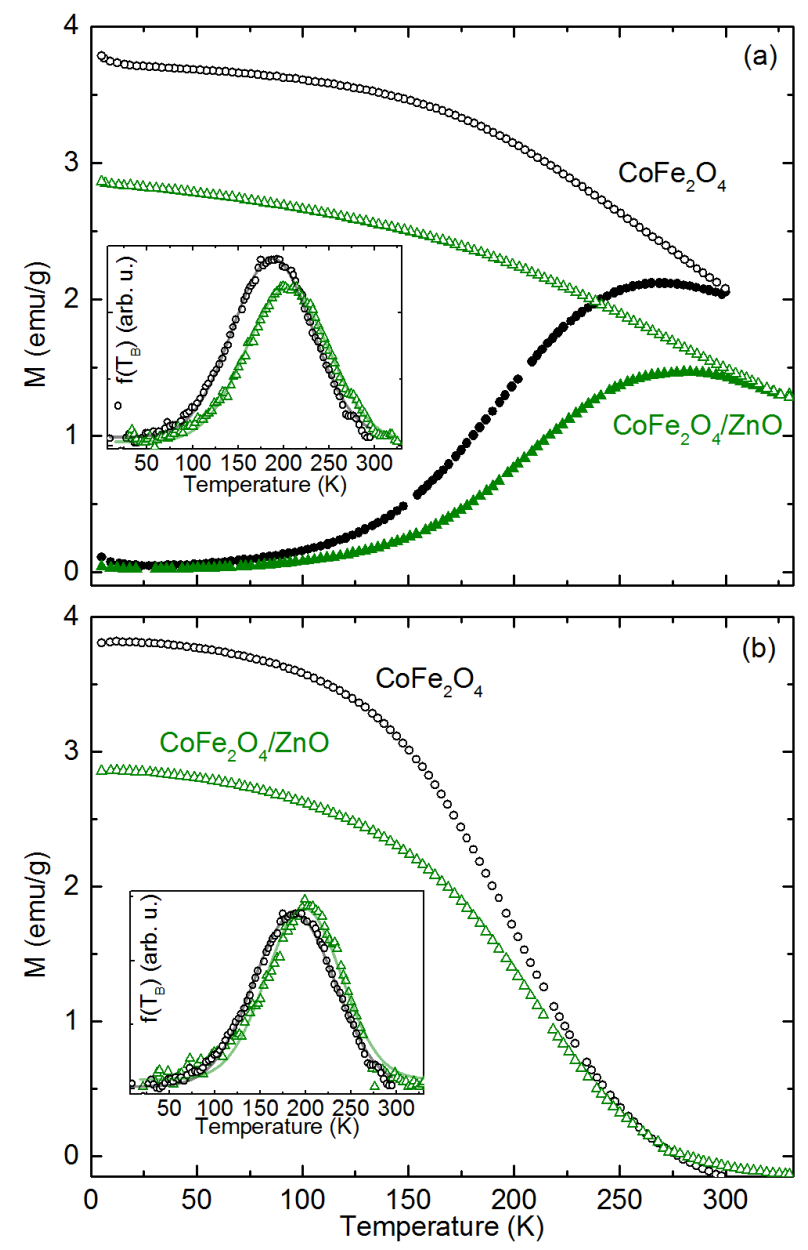

Figure 5. Temperature dependence of the magnetization for $\mathrm{CoFe}_{2} \mathrm{O}_{4}$ and $\mathrm{CoFe}_{2} \mathrm{O}_{4} / \mathrm{ZnO}$ NPs: (a) zero-field-cooled (full symbols) / field-cooled (open symbols) curves measured with an applied field 
of 50 Oe and (b) thermoremanent-magnetization curves measured upon heating after cooling down to $5 \mathrm{~K}$ with an applied field of $50 \mathrm{Oe}$. The insets indicate the distribution of blocking temperatures calculated in each case.

Hysteresis loops measured at $5 \mathrm{~K}$ (Figure 6a) reveal the typical shape expected for NPs with randomly oriented easy axes and, at low temperature, the coercive field $\left(\mathrm{H}_{\mathrm{C}}\right)$ and the reduced remanence value $\left(\mathrm{M}_{\mathrm{R}} / \mathrm{MS}_{\mathrm{S}}\right)$ are somewhat larger for the core/shell sample. In both cases $\mathrm{M}_{\mathrm{R}} / \mathrm{Ms}_{\mathrm{s}}$ is close to 0.5 , suggesting that the system presents uniaxial magnetic anisotropy $\left(M_{R} / M_{s}=0.5\right)$, rather than cubic anisotropy $\left(M_{R} / M_{s}=0.83\right)^{66}$. The low-temperature loops show a remarkable non-saturating trend and a large high-field susceptibility $(\chi \mathrm{HF})$ even for fields up to $50 \mathrm{kOe}$. The lack of saturation in magnetic NPs has been usually ascribed to the presence of surface spin disorder ${ }^{67}$ that can be also responsible for a magnetization increase at very low temperatures ${ }^{68}$, evident in the ZFC-FC curves of Co-ferrite cores (Figure 5a). In our case, the structural characterization revealed that the crystallite size of the $\mathrm{CoFe}_{2} \mathrm{O}_{4}$ is lower than the mean diameter determined by TEM, supporting the hypothesis of surface spin canting promoted by some crystalline disorder at the ferrite surface. In addition, $\chi_{\mathrm{HF}}$ decreases from $4.6(4) \cdot 10^{-4}$ to $3.9(4) \cdot 10^{-4} \mathrm{emu} / \mathrm{g}_{\mathrm{CFO} O e}$ for $\mathrm{CoFe}_{2} \mathrm{O}_{4}$ and $\mathrm{CoFe}_{2} \mathrm{O}_{4} / \mathrm{ZnO}$ NPs respectively, indicating that the $\mathrm{ZnO}$ shell contributes to decrease, to some extent, the surface spin disorder in the ferrite. At $300 \mathrm{~K}$ (Figure 6b), both samples exhibit a typical superparamagnetic behavior with negligible hysteresis and a saturation magnetization (Ms) lower than the lowtemperature values. Regarding the low-temperature Ms, it is close to the expected $90 \mathrm{emu} / \mathrm{g}$ for the bulk $\mathrm{CoFe}_{2} \mathrm{O}_{4}{ }^{69}$, although it is significantly reduced for $\mathrm{CoFe}_{2} \mathrm{O}_{4} / \mathrm{ZnO}$ NPs due to the contribution of the non-magnetic shell to the total mass of the sample. If we normalize the Ms values of core/shell NPs with the Co-ferrite mass obtained from the structural analysis, a 
Ms 98 emu/gCFO is obtained, reflecting the consistence of the magnetic characterization and the structural analysis.
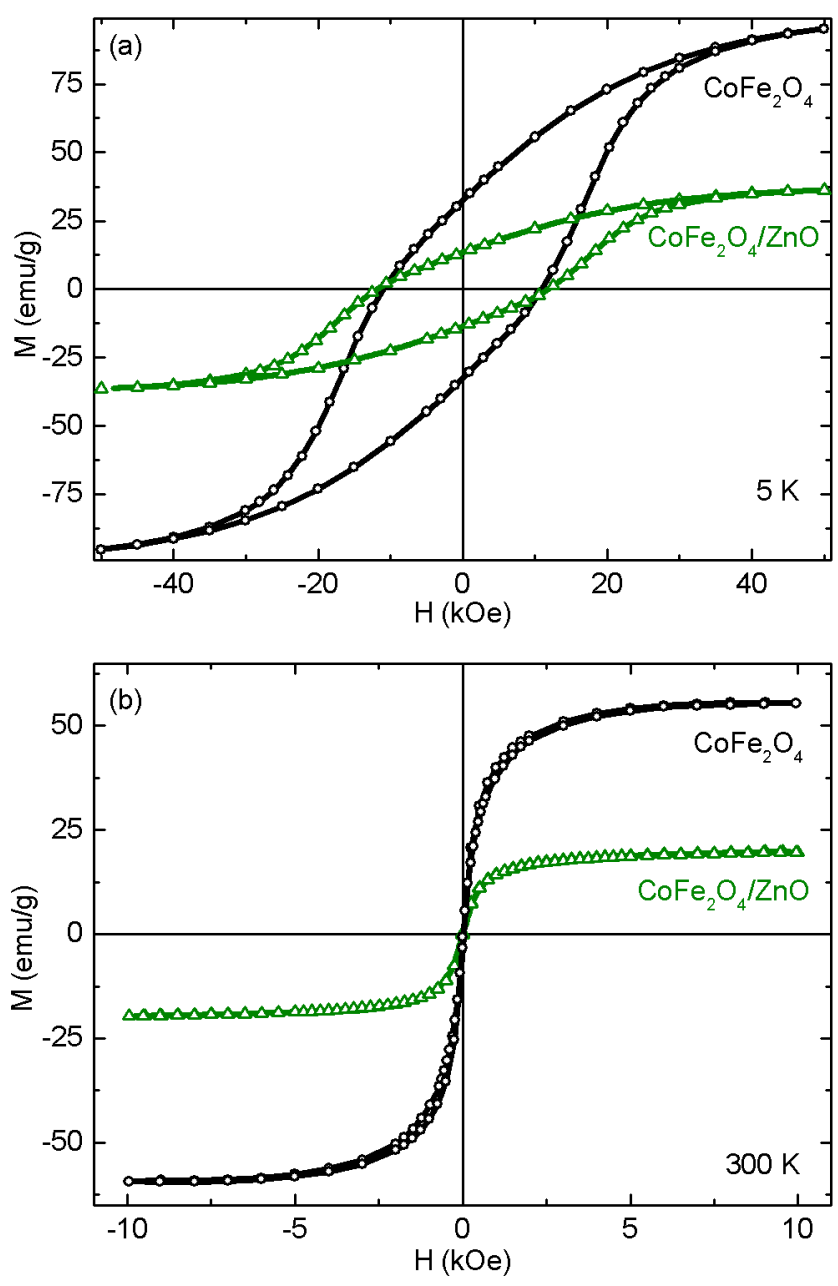

Figure 6. Hysteresis loops of $\mathrm{CoFe}_{2} \mathrm{O}_{4}$ and $\mathrm{CoFe}_{2} \mathrm{O}_{4} / \mathrm{ZnO}$ NPs measured at (a) $5 \mathrm{~K}$ and (b) $300 \mathrm{~K}$.

The small differences in the magnetic properties of both samples are reflected in $a \approx 7 \%$ increase in both $\left\langle T_{B}\right\rangle$ and $H_{C}$ for the core/shell sample. The longer synthesis time of the core/shell system and the presence of the $\mathrm{ZnO}$ layer may be promoting a slight increase in the effective anisotropy associated to a reduction in the surface crystalline disorder, as suggested by the previous analysis. Regardless of the origin of such differences, the effective magnetic anisotropy $\left(K_{e f f}\right)$ can be estimated either from the field or from the temperature 
dependence of the magnetization. By assuming the Néel relationship given by $K_{e f f} V=$ $\ln \left(\tau_{m} / \tau_{0}\right) k_{B}\left\langle T_{B}\right\rangle$, where $V$ is the magnetic volume, $k_{B}$ is the Boltzmann constant, $\tau_{m}$ and $\tau_{0}$ the measuring time (100 s) and the characteristic relaxation time $\left(10^{-10} \mathrm{~s}\right)$, respectively, $K_{e f f}$ can be calculated from the mean blocking temperature. Then, $K_{\text {eff }}$ is found to increase from $3.9(1) \cdot 10^{6} \mathrm{erg} / \mathrm{cm}^{3}$ for $\mathrm{CoFe}_{2} \mathrm{O}_{4}$ to $4.2(2) \cdot 10^{6} \mathrm{erg} / \mathrm{cm}^{3}$ for $\mathrm{CoFe}_{2} \mathrm{O}_{4} / \mathrm{ZnO}$ NPs. If we consider, instead, the coercivity of randomly oriented NPs with uniaxial anisotropy given by $H_{C}=$ $0.96 K_{e f f} / M_{S}$, where $M_{S}$ stands for the experimental saturation magnetization of the Coferrite in each sample, $K_{e f f} \approx 5.7(2) \cdot 10^{6}$ is obtained.

The estimations above are in good agreement with the expected values for nanostructured cobalt ferrite $\mathrm{e}^{70,71}$ and the overall DC magnetic characterization results are therefore successfully interpreted through the Stoner-Wohlfarth model for non-(or weakly) interacting NPs. As discussed before, the structural characterization suggests that the $\mathrm{ZnO}$ shell, being non-magnetic, is increasing the interparticle distance between magnetic cores and reducing the magnetic interactions. The magnitude of the dipole interaction energy can be estimated from the separation between particles $d$ and the NP magnetic moment $\mu$ through $T_{d}=$ $\mu_{0} \mu^{2} / k_{B} 4 \pi d^{3} \cdot{ }^{72}$ If we consider the experimental values, $T_{d}$ is reduced in our system from $114 \mathrm{~K}$ to $39 \mathrm{~K}$ due to the $\mathrm{ZnO}$ coating, well below the blocking temperature due to the magnetocrystalline anisotropy. Therefore, it is likely that the formation of $\mathrm{CoFe}_{2} \mathrm{O}_{4}$ aggregates suggested by DLS is hindered in the core/shell sample due to the reduced influence of interparticle interactions. In fact, other experimental studies have shown that a thin $(<2 \mathrm{~nm}) \mathrm{SiO}_{2}$ shell can reduce substantially the magnetic interactions in ensembles of carefully prepared $\gamma-\mathrm{Fe}_{2} \mathrm{O}_{3} / \mathrm{SiO}_{2}$ core/shell $\mathrm{NPs}^{73}$. 
Table 2. Summary of the magnetic characterization and the heating capability for single-phase $\mathrm{CoFe}_{2} \mathrm{O}_{4}$ and $\mathrm{CoFe}_{2} \mathrm{O}_{4} / \mathrm{ZnO}$ core/shell NPs: mean blocking temperature, $\left\langle T_{B}\right\rangle$, coercivity $\left(\mathrm{H}_{\mathrm{C}}\right)$ and saturation magnetization at $5 \mathrm{~K}\left(\mathrm{M}_{\mathrm{S}} 5 \mathrm{~K}\right)$, reduced remanence ratio $\left(\mathrm{M}_{\mathrm{R}} / \mathrm{M}_{\mathrm{S}}\right)$ at $5 \mathrm{~K}$, saturation magnetization at $300 \mathrm{~K}\left(\mathrm{M}_{\mathrm{S}} 300 \mathrm{~K}\right)$, experimental $\left(\mathrm{SPA}^{\mathrm{exp}}\right)$ and theoretical (SPA $\left.{ }^{\text {the }}\right)$ estimation of the specific power absorption.

\begin{tabular}{|l|c|c|c|c|c|c|c|}
\hline Sample & $\begin{array}{c}\left\langle T_{B}\right\rangle \\
(\mathrm{K})\end{array}$ & $\begin{array}{c}\mathrm{H}_{\mathrm{C}} 5 \mathrm{~K} \\
(\mathrm{kOe})\end{array}$ & $\begin{array}{c}\mathrm{M}_{\mathrm{S}} 5 \mathrm{~K} \\
(\mathrm{emu} / \mathrm{g})\end{array}$ & $\mathrm{M}_{\mathrm{R}} / \mathrm{M}_{\mathrm{S}} 5 \mathrm{~K}$ & $\mathrm{M}_{\mathrm{S}} 300 \mathrm{~K}$ & $\mathrm{SPA}^{\text {exp }}$ & $\mathrm{SP}^{\text {the }}$ \\
& $188(2)$ & $11.0(1)$ & $95.1(1)$ & $0.35(3)$ & $55.3(2)$ & $9.6(7)$ & $26.7(6)$ \\
$\mathrm{CoFe}_{2} \mathrm{O}_{4}$ & $201(6)$ & $11.8(1)$ & $36.3(1)$ & $0.43(1)$ & $20.0(1)$ & $2.5(2)$ & $2.0(1)$ \\
\hline $\mathrm{CoFe}_{2} \mathrm{O}_{4} / \mathrm{ZnO}$ & & & & & & & \\
\hline
\end{tabular}

\section{3 ac magnetic response}

The heating efficiency of a colloid for MFH is typically associated to the specific power absorption (SPA), i.e. the ability of a material to absorb energy (which will be turned into heat) from the alternating magnetic field. Alternatively, the SPA can be evaluated by the magnetic losses from the ac hysteresis loop area. In this way, we recorded magnetization loops for the samples dispersed in toluene under the application of a radiofrequency magnetic field with amplitude $H_{0}=80$ Oe and frequency $f=85 \mathrm{kHz}$, which are reported in Figure 7a. The areas of the loops reveal a SPA of 2.5(2) W/g for $\mathrm{CoFe}_{2} \mathrm{O}_{4} / \mathrm{ZnO}$ NPs and 9.6(7) W/g for $\mathrm{CoFe}_{2} \mathrm{O}_{4}$ cores, which are in good agreement with previous reports on the dynamic magnetic properties of Co-ferrite under similar experimental conditions ${ }^{15,74-76}$.

A simple model describing the heating efficiency of a magnetic fluid was presented by Rosensweig $^{77}$. In such approach, the relaxation of the magnetic moments of non-interacting single domain NPs is considered and a linear response of the magnetization with the applied 
field is assumed, being known as linear response theory (LRT), typically valid for low applied fields. Two types of relaxation processes can be present: a "viscous" Brown relaxation mechanism or a purely "magnetic" Néel process. As both can coexist, the relaxation mechanism and its effects on the SPA can be complicated and have led in the last years to several theoretical and experimental investigations ${ }^{3,78,79}$.

The Brownian relaxation time is a function of the viscosity of the medium $(\eta)$, the hydrodynamic volume $\left(V_{H}\right)$, the Boltzmann constant $\left(k_{B}\right)$ and the temperature $(T)$ :

$\tau_{B}=\frac{3 \eta V_{H}}{k_{B} T}($ equation 1$)$

While the "magnetic" relaxation time within a Néel process is given by $\tau_{N}=\tau_{0} e^{K_{e f f} V / k_{B} T}$, where $K_{e f f}$ is the effective magnetic anisotropy, $V$ the magnetic volume and $\tau_{0}$ the characteristic relaxation time. Rosensweig simplifies this problem by considering both relaxation mechanisms as independent, and consequently the effective relaxation time can be written as $1 / \tau_{\text {eff }}=1 / \tau_{B}+1 / \tau_{N}$, where the shorter time determines the relaxation process.

Due to the high magnetocrystalline anisotropy of $\mathrm{CoFe}_{2} \mathrm{O}_{4}, \mathrm{NPs}$ with typical magnetic sizes of 5-10 nm and hydrodynamic sizes of 10-50 nm usually follow a Brown relaxation mechanism ${ }^{15,77}$. In our case, in view of the high $K_{\text {eff }}$ estimated in the previous section, $\tau_{\mathrm{B}}$ is much smaller than $\tau_{N}$ and we can safely suppose that our particles follow a Brown relaxation process defined by equation 1 .

Therefore, in the frame of the LRT, the SPA results ${ }^{77}$ :

$S P A=\frac{\pi \chi_{0} f H_{0}^{2} 2 \pi f \tau_{B}}{1+\left(2 \pi f \tau_{B}\right)^{2}}($ equation 2$)$ 
where $\chi_{0}=M_{S}^{2} V /\left(3 k_{B} T\right)$ is the initial susceptibility of the system and $H_{0}$ and $f$ are the amplitude and frequency of the excitation field. The SPA depends on the magnetic size and Ms through $\chi_{0}$ and on the hydrodynamic size through $\tau_{B}$. As a result, when $2 \pi f \tau_{B}=1$ the SPA is a maximum and $\mathrm{DH}_{\mathrm{H}}$ will be optimum.

The existence of an optimum $D_{H}$ close to $20 \mathrm{~nm}$ is evidenced in the inset of Figure $7 \mathrm{~b}$, where the theoretical SPA is plotted as a function of $\mathrm{DH}$ according to equation 2 and considering all the experimental conditions (temperature, viscosity of the medium, field amplitude, frequency and magnetic volume). Next, bearing in mind the distribution of $\mathrm{D}_{\mathrm{H}}$ reported in Figure 4, we can reconstruct the distribution of theoretical SPA rates expected for both samples (Figure 7b). By integrating such distributions, the overall theoretical SPA rates were calculated and compared with the experimental values, as shown in Figure $7 \mathrm{c}$ and table 2. It is observed that the theoretical SPA value for $\mathrm{CoFe}_{2} \mathrm{O}_{4} / \mathrm{ZnO}$ NPs is in excellent agreement with the experiments. However, the situation is different for $\mathrm{CoFe}_{2} \mathrm{O}_{4}$, whose value is less than half of the theoretical prediction. The difference should be ascribed to an oversimplification of the model that neglects the dependence of the SPA on magnetic interactions, which are suggested by the experiments presented in the previous sections. 

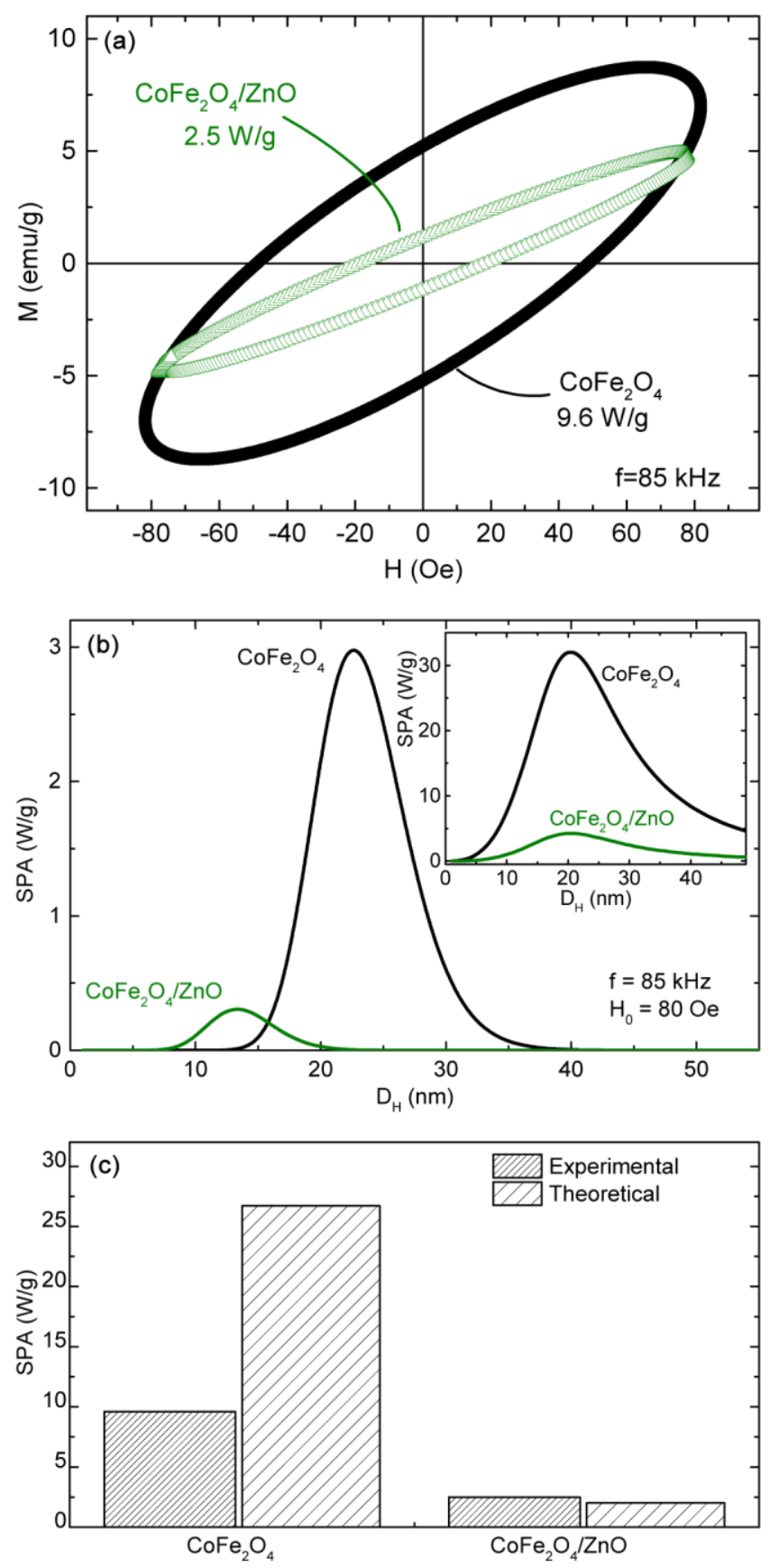

Figure 7. (a) Field-dependence of the magnetization during the application of an alternating field with amplitude $\mathrm{H}_{0}=80$ Oe and $\mathrm{f}=85 \mathrm{kHz}$. The experimental SPA rates obtained from the area of each loop are indicated. (b) Distribution of SPA rates estimated by considering equation 2, the experimental distribution of $\mathrm{D}_{\mathrm{H}}$ from DLS experiments shown in Figure 3 and the experimental 
conditions. The inset shows the distribution of theoretical SPA as a function of $\mathrm{D}_{\mathrm{H}}$. (c) Comparison of the experimental and theoretical SPA rates.

In the last few years, several works have been devoted to understand the effects of interactions on the heating efficiency of magnetic colloids ${ }^{22,78,80,81}$. In the case of NPs relaxing by Brown's mechanism, it is normally accepted that interactions push down the SPA due to the dependence of $\tau_{B}$ with $V_{H}$. This is a reason why highly anisotropic NPs usually have a very different output when measured in biological media that favor their aggregation $^{21}$. In fact, it was predicted by Montecarlo simulations that dipolar interactions can help to increase the heating ability of Brown-relaxing NPs only in the very high field's regime, while interactions promote lower SPAs for low applied fields ${ }^{82}$.

In this context, the possibility of tuning the interactions by a thin non-magnetic shell could be interesting ${ }^{83}$. In our case, although the SPA is significantly reduced for the core/shell sample, it is worth noting that the non-magnetic $\mathrm{ZnO}$ shell allows the reduction of the dipolar interactions between particles by controlling their mean separation distance. As a consequence, the SPA rate is correctly predicted by the LRT and the NPs are likely to be less-sensitive to the media in which they are dispersed, which is a key aspect for keeping high SPA values in physiological media ${ }^{12,21,22}$. In this sense, the introduction of a nonmagnetic coating, apart from exploiting its optical functionality, could be useful to decrease the influence of magnetic interactions on the heating efficiency.

\subsection{Optical response}


Once the effects of the structural, morphological, rheological and $d c$ and $a c$ magnetic properties were analyzed, we can turn our attention to the optical response of the material. UV-Vis and photoluminescence (PL) spectra, the latter acquired by using a fixed excitation wavelength $\left(\lambda_{\mathrm{EX}}\right)$ of $350 \mathrm{~nm}$, are reported in Figure 8 . The experiments were conducted for both $\mathrm{CoFe}_{2} \mathrm{O}_{4} / \mathrm{ZnO}$ and $\mathrm{CoFe}_{2} \mathrm{O}_{4}$ samples, and, for comparison, single-phase $\mathrm{ZnO}$ NPs with a mean size of $\sim 4 \mathrm{~nm}$ obtained by a similar method ${ }^{84}$, were also analyzed.

Single-phase ZnO NPs exhibit an absorption peak at $\lambda \sim 280 \mathrm{~nm}$, which is significantly lower than the wavelength associated to the bandgap of bulk $\mathrm{ZnO}(\sim 3.3 \mathrm{eV})$, typically $\lambda \sim 365$ $\mathrm{nm}^{85,86}$. The shift of the absorption peak to lower values of $\lambda$, usually observed in $\mathrm{ZnO}$ quantum dots, is ascribed to finite size effects and it can be shifted down to $\lambda \sim 265 \mathrm{~nm}$ for 1 $\mathrm{nm} \mathrm{ZnO}$ clusters $^{87}$. In the case of our core/shell NPs, the absorption peak is shifted to lower values but, at the same time, is also significantly broader. Such broadening has already been observed in other $\mathrm{CoFe}_{2} \mathrm{O}_{4}-\mathrm{ZnO}$ composites ${ }^{43,88}$ and has been also predicted by theoretical studies on $\mathrm{ZnO}$ nanowires by considering the effects of $\mathrm{Zn}$ and $\mathrm{O}$ vacancies on the optical properties $^{89}$.

Regarding the PL spectra shown in Figure 8b, single-phase ZnO NPs present multiple emission peaks in the near-UV $(\sim 395 \mathrm{~nm})$ and the visible region $(425 \mathrm{~nm}$ and $450 \mathrm{~nm})$, while $\mathrm{CoFe}_{2} \mathrm{O}_{4} / \mathrm{ZnO}$ NPs display a broader emission in the visible region with a maximum at 450 $\mathrm{nm}$ and a narrower maximum at $520 \mathrm{~nm}$. 

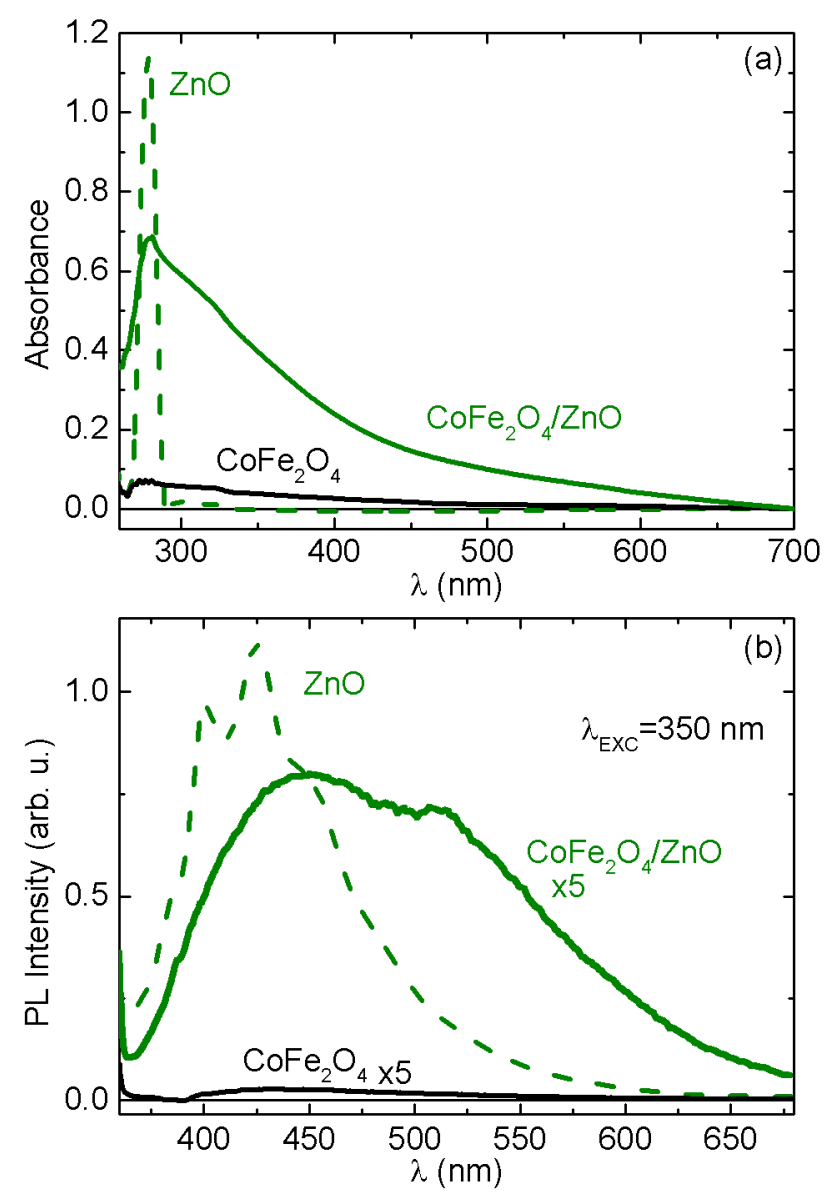

Figure 8. (a) UV-visible and (b) photoluminescence spectra (under an excitation wavelength of 350 nm) for single-phase $\mathrm{ZnO}$ and core/shell $\mathrm{CoFe}_{2} \mathrm{O}_{4} / \mathrm{ZnO}$. For comparison, the same measurements were performed for $\mathrm{CoFe}_{2} \mathrm{O}_{4}$ cores.

Although the precise mechanism responsible for the $\mathrm{PL}$ of $\mathrm{ZnO}$ is still under discussion $^{52,85,86,90}$, it is accepted that different defects result in energy levels within the $\mathrm{ZnO}$ bandgap $^{52}$ that are responsible for the multiple observations of emission lines in the visible range. Both bulk and nanostructured $\mathrm{ZnO}$ show emission at the near UV edge $(380 \mathrm{~nm})$ and also at the blue $(425$ and $468 \mathrm{~nm})$ and green band $(521 \mathrm{~nm})^{91,92}$. While the near band edge UV emission is associated to band gap excitons, the blue and green emissions are assigned to recombination processes of acceptor defects from $\mathrm{Zn}$ interstitial and oxygen vacancies ${ }^{93}$. 
It has also been established that the ratio between the visible and UV PL intensity is closely related to the size and the fabrication method: while a fine $\mathrm{UV}$ emission is observed in $\mathrm{ZnO}$ quantum dots and also in highly crystalline $\mathrm{ZnO}$, size distribution and low-temperature fabrication techniques usually lead to inhomogeneous broadening of the emission in the visible range ${ }^{86}$. Therefore, the differences between the absorption and UV-vis spectra of single-phase $\mathrm{ZnO}$ and core/shell NPs can be ascribed to the presence of a larger density of defects in the crystalline structure resulting from the shell-morphology of the nanocrystals in the latter. This is supported by the structural characterization, which reveals that the $\mathrm{ZnO}$ shell is not single-crystalline but it is formed by several very small grains. In addition, the possibility of interface interdiffusion cannot be ruled out, particularly given that this effect could contribute to the inhomogeneous broadening and the observed red-shift of both the absorption and photoluminescence spectra, as was reported e.g. for Fe-doped ZnO NPs ${ }^{93,94}$.

In this work we showed that the PL can be controlled by choosing the $\mathrm{ZnO}$ morphology, however it should be pointed out that the PL can be further tuned modifying the surface defects by changing the $\mathrm{ZnO}$ shell thickness ${ }^{39}$ or by coordinating the NPs with different polymers ${ }^{31,86}$. Thanks to their optical response, the NPs can be applied as contrast agents in optical fluorescence microscopy in vitro. The incorporation of imaging functionalities to the NPs could contribute to the future development of magnetic fluid hyperthermia and its clinical application by monitoring their presence in the intracellular medium in vitro through the optical output of the $\mathrm{ZnO}$ shell in fluorescence microscopy. For example, labeling NPs suitable for MFH by optical imaging probes can help to correlate precisely the cell response and the intracellular presence of the NPs and can contribute to clarify the cell death mechanisms. Given the widespread use of fluorescence microscopy in biological sciences, 
its good sensitivity, as well as the real-time imaging capability and the great availability of fluorophores that can be tailored to specific biological applications ${ }^{7,8}$, the co-localization of the NPs by optical means can be very useful. However, further work is required to evaluate and optimize the optical response during biological experiments.

\section{Conclusions}

In this work we synthesized $7 \mathrm{~nm} \mathrm{CoFe}_{2} \mathrm{O}_{4}$ and $10 \mathrm{~nm} \mathrm{CoFe}_{2} \mathrm{O}_{4} / \mathrm{ZnO}$ core/shell nanoparticles and we evaluated the effects of the structure and morphology on the $d c$ and $a c$ magnetic behavior and on the optical response. The single phase $\mathrm{CoFe}_{2} \mathrm{O}_{4}$ nanoparticles are superparamagnetic at room temperature and present an effective magnetic anisotropy around $\mathrm{K}_{\mathrm{eff}} \approx 3.9(1) \cdot 10^{6} \mathrm{erg} / \mathrm{cm}^{3}$. On the other hand, the core/shell system exhibits a slightly larger energy barrier, $K_{\text {eff }} \approx 4.2(2) \cdot 10^{6} \mathrm{erg} / \mathrm{cm}^{3}$, as reflected by the greater coercivity and blocking temperature, which can be explained by considering the reduction of the surface crystalline disorder in the ferrite. The dipolar interparticle interactions are being reduced in the core/shell system as a result of the thin $\mathrm{ZnO}$ layer that increases the mean separation distance between magnetic cores. Being highly anisotropic, the nanoparticles follow a viscous relaxation process under an $a c$ magnetic field and the specific power absorption rate of the core/shell system can be accurately predicted by the linear response theory because of the reduced influence of magnetic interactions.

In addition, we found that the morphology of the $\mathrm{ZnO}$ capping layer promotes an inhomogeneous broadening of the absorption and emission bands and a shift of the photoluminescence and absorption energies toward the visible region, as evidenced by the 
comparison with single-phase $\mathrm{ZnO}$ nanoparticles. Such behavior is ascribed to the greater density of surface defects due to the shell morphology and also to the interface interdiffusion. The wide photoluminescence in the visible range presented by the core/shell system is a promising result for the development of a bifunctional material acting as an inorganic optical marker suitable for magnetic fluid hyperthermia. At the same time, the $\mathrm{ZnO}$ capping could be a potential solution for the design of materials with reduced magnetostatic interactions and diminished nanoparticle agglomeration, which would be highly interesting for applications in magnetic fluid hyperthermia. Finally, it is worth mentioning that further work oriented to analyze the passivation of the cobalt ferrite by the $\mathrm{ZnO}$ shell and to evaluate the effects of the inductive heating on the optical properties of the system could provide important information for the development of oxide multifunctional nanosystems for biological applications.

\section{Acknowledgement}

The authors are thankful to Argentinian governmental ANPCyT and CONICET for the financial support of the work through Grant No. PICT-2015-0883 and Grant No. PIP 11220110100519, respectively, and UNCuyo for support through Grants No. 06/C527 and 06/C528. The authors are also indebted to the people from the Laboratory of Analytical Chemistry of the Centro Atómico Bariloche for the UV-Vis and PL measurements. GL would like to thank Elisa Baggio-Saitovitch for her support, CONICET and CNPq for fellowships during the work and the LABNANO/CBPF for technical support during electron microscopy. 


\section{References}

(1) Pankhurst, Q. A.; Thanh, N. T. K.; Jones, S. K.; Dobson, J. Progress in Applications of Magnetic Nanoparticles in Biomedicine. J. Phys. D. Appl. Phys. 2009, 42 (22), 224001.

(2) Ortega, D.; Pankhurst, Q. A. Magnetic Hyperthermia; 2013; Vol. 1, pp 60-88.

(3) Dennis, C. L.; Ivkov, R. Physics of Heat Generation Using Magnetic Nanoparticles for Hyperthermia. Int J Hyperth. 2013, 29 (8), 715-729.

(4) Périgo, E. A.; Hemery, G.; Sandre, O.; Ortega, D.; Garaio, E.; Plazaola, F.; Teran, F. J. Fundamentals and Advances in Magnetic Hyperthermia. Appl. Phys. Rev. 2015, 2 (4), 41302.

(5) Blanco-Andujar, C.; Walter, A.; Cotin, G.; Bordeianu, C.; Mertz, D.; Felder-Flesch, D.; Begin-Colin, S. Design of Iron Oxide-Based Nanoparticles for MRI and Magnetic Hyperthermia. Nanomedicine 2016, 11 (14), 1889-1910.

(6) Cheng, Z.; Al Zaki, A.; Hui, J. Z.; Muzykantov, V. R.; Tsourkas, A. Multifunctional Nanoparticles: Cost versus Benefit of Adding Targeting and Imaging Capabilities. Science 2012, 338 (6109), 903-910.

(7) Pelaz, B.; Alexiou, C.; Alvarez-Puebla, R. A.; Alves, F.; Andrews, A. M.; Ashraf, S.;

Balogh, L. P.; Ballerini, L.; Bestetti, A.; Brendel, C.; et al. Diverse Applications of Nanomedicine. ACS Nano 2017, 11 (3), 2313-2381.

(8) Lee, D.-E.; Koo, H.; Sun, I.-C.; Ryu, J. H.; Kim, K.; Kwon, I. C. Multifunctional Nanoparticles for Multimodal Imaging and Theragnosis. Chem. Soc. Rev. 2012, 41 (7), 2656-2672. 
(9) Lee, N.; Yoo, D.; Ling, D.; Cho, M. H.; Hyeon, T.; Cheon, J. Iron Oxide Based

Nanoparticles for Multimodal Imaging and Magnetoresponsive Therapy. Chem. Rev. 2015, 115 (19), 10637-10689.

(10) Lee, J. H.; Jang, J. T.; Choi, J. S.; Moon, S. H.; Noh, S. H.; Kim, J. W.; Kim, J. G.; Kim, I. S.; Park, K. I.; Cheon, J. Exchange-Coupled Magnetic Nanoparticles for Efficient Heat Induction. Nat. Nanotechnol. 2011, 6 (7), 418-422.

(11) Das, R.; Alonso, J.; Nemati Porshokouh, Z.; Kalappattil, V.; Torres, D.; Phan, M.-H.; Garaio, E.; García, J. Á.; Sanchez Llamazares, J. L.; Srikanth, H. Tunable High Aspect Ratio Iron Oxide Nanorods for Enhanced Hyperthermia. J. Phys. Chem. C 2016, 120 (18), 1008610093.

Andreu, I.; Natividad, E.; Solozábal, L.; Roubeau, O. Nano-Objects for Addressing the Control of Nanoparticle Arrangement and Performance in Magnetic Hyperthermia. ACS Nano 2015, 9 (2), 1408-1419.

(13) Guardia, P.; Di Corato, R.; Lartigue, L.; Wilhelm, C.; Espinosa, A.; Garcia-Hernandez, M.; Gazeau, F.; Manna, L.; Pellegrino, T. Water-Soluble Iron Oxide Nanocubes with High Values of Specific Absorption Rate for Cancer Cell Hyperthermia Treatment. ACS Nano 2012, 6 (4), 3080-3091.

(14) Hugounenq, P.; Levy, M.; Alloyeau, D.; Lartigue, L.; Dubois, E.; Cabuil, V.; Ricolleau, C.; Roux, S.; Wilhelm, C.; Gazeau, F.; et al. Iron Oxide Monocrystalline Nanoflowers for Highly Efficient Magnetic Hyperthermia. J. Phys. Chem. C 2012, 116 (29), 15702-15712.

(15) Lima, E.; De Biasi, E.; Zysler, R. D.; Vasquez Mansilla, M.; Mojica-Pisciotti, M. L.; Torres, T. E.; Calatayud, M. P.; Marquina, C.; Ricardo Ibarra, M.; Goya, G. F. Relaxation Time Diagram for Identifying Heat Generation Mechanisms in Magnetic Fluid Hyperthermia. $J$. 
Nanoparticle Res. 2014, 16 (12), 2791.

(16) Kozissnik, B.; Bohorquez, A. C.; Dobson, J.; Rinaldi, C. Magnetic Fluid Hyperthermia: Advances, Challenges, and Opportunity. Int. J. Hyperthermia 2013, 29 (8), 706-714.

(17) Löwa, N.; Seidel, M.; Radon, P.; Wiekhorst, F. Magnetic Nanoparticles in Different Biological Environments Analyzed by Magnetic Particle Spectroscopy. J. Magn. Magn. Mater. 2017, 427 (1), 133-138.

(18) Corot, C.; Robert, P.; Idée, J. M.; Port, M. Recent Advances in Iron Oxide Nanocrystal Technology for Medical Imaging. Adv. Drug Deliv. Rev. 2006, 58 (14), 1471-1504.

(19) Cho, M.; Cervadoro, A.; Ramirez, M.; Stigliano, C.; Brazdeikis, A.; Colvin, V.; Civera, P.; Key, J.; Decuzzi, P. Assembly of Iron Oxide Nanocubes for Enhanced Cancer Hyperthermia and Magnetic Resonance Imaging. Nanomaterials 2017, 7 (4), 72.

(20) Yoo, D.; Lee, J.-H.; Shin, T.-H.; Cheon, J. Theranostic Magnetic Nanoparticles. Acc. Chem. Res. 2011, 44 (10), 863-874.

(21) Di Corato, R.; Espinosa, A.; Lartigue, L.; Tharaud, M.; Chat, S.; Pellegrino, T.; Ménager, C.; Gazeau, F.; Wilhelm, C. Magnetic Hyperthermia Efficiency in the Cellular Environment Fordifferent Nanoparticle Designs. Biomaterials 2014, 35 (24), 6400-6411.

(22) Sanz, B.; Calatayud, M. P.; De Biasi, E.; Lima, E.; Mansilla, M. V.; Zysler, R. D.; Ibarra, M. R.; Goya, G. F. In Silico before In Vivo: How to Predict the Heating Efficiency of Magnetic Nanoparticles within the Intracellular Space. Sci. Rep. 2016, 6 (1), 38733.

(23) Chen, Z.; Yin, J. J.; Zhou, Y. T.; Zhang, Y.; Song, L.; Song, M.; Hu, S.; Gu, N. Dual Enzyme-like Activities of Iron Oxide Nanoparticles and Their Implication for Diminishing Cytotoxicity. ACS Nano 2012, 6 (5), 4001-4012. 
(24) Chiu-Lam, A.; Rinaldi, C. Nanoscale Thermal Phenomena in the Vicinity of Magnetic Nanoparticles in Alternating Magnetic Fields. Adv. Funct. Mater. 2016, 26 (22), 3933-3941.

(25) Connord, V.; Clerc, P.; Hallali, N.; El Hajj Diab, D.; Fourmy, D.; Gigoux, V.; Carrey, J. Real-Time Analysis of Magnetic Hyperthermia Experiments on Living Cells under a Confocal Microscope. Small 2015, 11 (20), 2437-2445.

(26) Blanco-Andujar, C.; Ortega, D.; Southern, P.; Nesbitt, S. a; Thanh, N. T. K.; Pankhurst, Q. a. Real-Time Tracking of Delayed-Onset Cellular Apoptosis Induced by Intracellular Magnetic Hyperthermia. Nanomedicine 2016, 11 (2), 121-136.

(27) Clerc, P.; Jeanjean, P.; Hallalli, N.; Gougeon, M.; Pipy, B.; Carrey, J.; Fourmy, D.; Gigoux, V. Targeted Magnetic Intra-Lysosomal Hyperthermia Produces Lysosomal Reactive Oxygen Species and Causes Caspase-1 Dependent Cell Death. J. Control. Release 2018, 270, 120134.

(28) Michalet, X.; Pinaud, F. F. Quantum Dots for Live Cells, in Vivo Imaging, and Diagnostics. Science (80-. ). 2005, 307 (538), 538-545.

(29) Louis, C.; Pluchery, O. Gold Nanoparticles for Physics, Chemistry and Biology; World Scientific, 2012.

(30) Wegner, K. D.; Hildebrandt, N. Quantum Dots: Bright and Versatile in Vitro and in Vivo Fluorescence Imaging Biosensors. Chem. Soc. Rev. 2015, 44 (14), 4792-4834.

(31) Fu, Y.; Du, X.; Kulinich, S. A.; Qiu, J.; Qin, W.; Li, R.; Sun, J.; Liu, J. Stable Aqueous Dispersion of ZnO Quantum Dots with Strong Blue Emission via Simple Solution Route. J. Am. Chem. Soc. 2007, 129 (51), 16029-16033.

Li, W.-J.; Chen, Y.-T.; Huang, P.-H.; Yang, T.-L.; Huang, J.-J. Cancer Cell Identification by Bi-Color $\mathrm{ZnO}$ and $\mathrm{TiO}_{2}$ Nanowires. J. Biophotonics 2017, 10 (1), 92-97. 
(33) Ye, D. X.; Ma, Y. Y.; Zhao, W.; Cao, H. M.; Kong, J. L.; Xiong, H. M.; Möhwald, H. ZnOBased Nanoplatforms for Labeling and Treatment of Mouse Tumors without Detectable Toxic Side Effects. ACS Nano 2016, 10 (4), 4294-4300.

(34) Zeng, H.; Sun, S. Syntheses, Properties, and Potential Applications of Multicomponent Magnetic Nanoparticles. Adv. Funct. Mater. 2008, 18 (3), 391-400.

(35) Lavorato, G. C.; Peddis, D.; Lima, E.; Troiani, H. E.; Agostinelli, E.; Fiorani, D.; Zysler, R. D.; Winkler, E. L. Magnetic Interactions and Energy Barrier Enhancement in Core/Shell Bimagnetic Nanoparticles. J. Phys. Chem. C 2015, 119 (27), 15755-15762.

(36) Lavorato, G. C.; Lima, E.; Troiani, H. E.; Zysler, R. D.; Winkler, E. L. Tuning the Coercivity and Exchange Bias by Controlling the Interface Coupling in Bimagnetic Core/shell Nanoparticles. Nanoscale 2017, 9 (29), 10240-10247.

(37) Lavorato, G. C.; Lima, E.; Troiani, H. E.; Zysler, R. D.; Winkler, E. L. Exchange-Coupling in Thermal Annealed Bimagnetic Core/shell Nanoparticles. J. Alloys Compd. 2015, 633, $333-337$.

(38) Skeete, Z.; Cheng, H.; Crew, E.; Lin, L.; Zhao, W.; Joseph, P.; Shan, S.; Cronk, H.; Luo, J.; Li, Y.; et al. Design of Functional Nanoparticles and Assemblies for Theranostic Applications. ACS Appl. Mater. Interfaces 2014, 6 (24), 21752-21768.

(39) Liu, H.; Wu, J.; Min, J. H.; Zhang, X.; Kim, Y. K. Tunable Synthesis and Multifunctionalities of $\mathrm{Fe}_{3} \mathrm{O}_{4}-\mathrm{ZnO}$ Hybrid Core-Shell Nanocrystals. Mater. Res. Bull. 2013, $48(2), 551-558$.

Chiu, W.; Khiew, P.; Cloke, M.; Isa, D.; Lim, H.; Tan, T.; Huang, N.; Radiman, S.; Abd-

Shukor, R.; Hamid, M. A. A.; et al. Heterogeneous Seeded Growth: Synthesis and Characterization of Bifunctional $\mathrm{Fe}_{3} \mathrm{O}_{4} / \mathrm{ZnO}$ Core/Shell Nanocrystals. J. Phys. Chem. C 
2010, 114 (18), 8212-8218.

(41) Zhou, T.; Lu, M.; Zhang, Z.; Gong, H.; Chin, W. S.; Liu, B. Synthesis and Characterization of Multifunctional FePt/ZnO Core/Shell Nanoparticles. Adv. Mater. 2010, 22 (3), 403-406.

Cho, N.-H.; Cheong, T.-C.; Min, J. H.; Wu, J. H.; Lee, S. J.; Kim, D.; Yang, J.-S.; Kim, S.;

Kim, Y. K.; Seong, S.-Y. A Multifunctional Core-Shell Nanoparticle for Dendritic CellBased Cancer Immunotherapy. Nat. Nanotechnol. 2011, 6 (10), 675-682.

(43) Venkatesha, N.; Qurishi, Y.; Atreya, H. S.; Srivastava, C. ZnO Coated $\mathrm{CoFe}_{2} \mathrm{O}_{4}$ Nanoparticles for Multimodal Bio-Imaging. RSC Adv. 2016, 6 (23), 18843-18851.

(44) Torres, T. E.; Roca, A. G.; Morales, M. P.; Ibarra, A.; Marquina, C.; Ibarra, M. R.; Goya, G. F. Magnetic Properties and Energy Absorption of $\mathrm{CoFe}_{2} \mathrm{O}_{4}$ Nanoparticles for Magnetic Hyperthermia. J. Phys. Conf. Ser. 2010, 200 (7), 72101.

(45) Kim, D.-H.; Nikles, D. E.; Johnson, D. T.; Brazel, C. S. Heat Generation of Aqueously Dispersed $\mathrm{CoFe}_{2} \mathrm{O}_{4}$ Nanoparticles as Heating Agents for Magnetically Activated Drug Delivery and Hyperthermia. J. Magn. Magn. Mater. 2008, 320 (19), 2390-2396.

(46) Verde, E. L.; Landi, G. T.; Gomes, J. A.; Sousa, M. H.; Bakuzis, A. F. Magnetic Hyperthermia Investigation of Cobalt Ferrite Nanoparticles: Comparison between Experiment, Linear Response Theory, and Dynamic Hysteresis Simulations. J. Appl. Phys. 2012, $111(12), 123902$.

(47) Çelik, Ö.; Can, M. M.; Firat, T. Size Dependent Heating Ability of $\mathrm{CoFe}_{2} \mathrm{O}_{4}$ Nanoparticles in AC Magnetic Field for Magnetic Nanofluid Hyperthermia. J. Nanoparticle Res. 2014, 16 (3), 2321.

(48) Soler, M. A. G.; Lima, E. C. D.; da Silva, S. W.; Melo, T. F. O.; Pimenta, A. C. M.; Sinnecker, J. P.; Azevedo, R. B.; Garg, V. K.; Oliveira, A. C.; Novak, M. A.; et al. Aging 
Investigation of Cobalt Ferrite Nanoparticles in Low pH Magnetic Fluid. Langmuir 2007, 23 (19), 9611-9617.

(49) Schultz-Sikma, E. A.; Joshi, H. M.; Ma, Q.; MacRenaris, K. W.; Eckermann, A. L.; Dravid, V. P.; Meade, T. J. Probing the Chemical Stability of Mixed Ferrites: Implications for Magnetic Resonance Contrast Agent Design. Chem. Mater. 2011, 23 (10), 2657-2664.

(50) Zhang, T.; Stilwell, J. L.; Gerion, D.; Ding, L.; Elboudwarej, O.; Cooke, P. A.; Gray, J. W.; Alivisatos, A. P.; Chen, F. F. Cellular Effect of High Doses of Silica-Coated Quantum Dot Profiled with High Throughput Gene Expression Analysis and High Content Cellomics Measurements. Nano Lett. 2006, 6 (4), 800-808.

(51) Wang, Z. L. Nanostructures of Zinc Oxide. Mater. Today 2004, 7 (6), 26-33.

(52) Djurišić, A. B.; Chen, X.; Leung, Y. H.; Man Ching Ng, A. ZnO Nanostructures: Growth, Properties and Applications. J. Mater. Chem. 2012, 22 (14), 6526.

(53) Sun, S.; Zeng, H. Size-Controlled Synthesis of Magnetite Nanoparticles. J. Am. Chem. Soc. 2002, No. 31, 8204-8205.

(54) van Embden, J.; Chesman, A. S. R.; Jasieniak, J. J. The Heat-Up Synthesis of Colloidal Nanocrystals. Chem. Mater. 2015, 27 (7), 2246-2285.

Lima, E.; Winkler, E. L.; Tobia, D.; Troiani, H. E.; Zysler, R. D.; Agostinelli, E.; Fiorani, D. Bimagnetic CoO Core/ $\mathrm{CoFe}_{2} \mathrm{O}_{4}$ Shell Nanoparticles: Synthesis and Magnetic Properties. Chem. Mater. 2012, 24 (3), 512-516.

(56) Lavorato, G. C.; Lima Jr, E.; Tobia, D.; Fiorani, D.; Troiani, H. E.; Zysler, R. D.; Winkler, E. L. Size Effects in Bimagnetic $\mathrm{CoO} / \mathrm{CoFe}_{2} \mathrm{O}_{4}$ Core/shell Nanoparticles. Nanotechnology 2014, 25 (35), 355704. 
(57) Rodríguez-Carvajal, J. Recent Advances in Magnetic Structure Determination by Neutron Powder Diffraction. Phys. B Condens. Matter 1993, 192, 55.

(58) Vargas, J. M.; Zysler, R. D. Tailoring the Size in Colloidal Iron Oxide Magnetic Nanoparticles. Nanotechnology 2005, 16 (9), 1474-1476.

Lassenberger, A.; Grünewald, T. A.; Van Oostrum, P. D. J.; Rennhofer, H.; Amenitsch, H.; Zirbs, R.; Lichtenegger, H. C.; Reimhult, E. Monodisperse Iron Oxide Nanoparticles by Thermal Decomposition: Elucidating Particle Formation by Second-Resolved in Situ SmallAngle X-Ray Scattering. Chem. Mater. 2017, 29 (10), 4511-4522.

(60) Sun, S.; Zeng, H.; Robinson, D. B.; Raoux, S.; Rice, P. M.; Wang, S. X.; Li, G. Monodisperse $\mathrm{MFe}_{2} \mathrm{O}_{4}(\mathrm{M}=\mathrm{Fe}, \mathrm{Co}, \mathrm{Mn})$ Nanoparticles. J. Am. Chem. Soc. 2004, 126 (1), $273-279$.

(61) Skoropata, E.; Desautels, R. D.; Chi, C. C.; Ouyang, H.; Freeland, J. W.; Van Lierop, J. Magnetism of Iron Oxide Based Core-Shell Nanoparticles from Interface Mixing with Enhanced Spin-Orbit Coupling. Phys. Rev. B - Condens. Matter Mater. Phys. 2014, 89, 1-9.

(62) López-Ortega, A.; Estrader, M.; Salazar-Alvarez, G.; Estradé, S.; Golosovsky, I. V.; Dumas, R. K.; Keavney, D. J.; Vasilakaki, M.; Trohidou, K. N.; Sort, J.; et al. Strongly Exchange Coupled Inverse Ferrimagnetic Soft/hard, MnxFe3-xO4/FexMn3-xO4, Core/shell Heterostructured Nanoparticles. Nanoscale 2012, 4 (16), 5138-5147.

(63) Zhang, L.; He, R.; Gu, H.-C. Oleic Acid Coating on the Monodisperse Magnetite Nanoparticles. Appl. Surf. Sci. 2006, 253 (5), 2611-2617.

(64) Liu, X.; Pichon, B. P.; Ulhaq, C.; Lefèvre, C.; Grenèche, J.-M.; Bégin, D.; Bégin-Colin, S. Systematic Study of Exchange Coupling in Core-Shell $\mathrm{Fe}_{3-\delta} \mathrm{O}_{4} @ \mathrm{CoO}$ Nanoparticles. Chem. Mater. 2015, 27 (11), 4073-4081. 
(65) Dreyer, A.; Feld, A.; Kornowski, A.; Yilmaz, E. D.; Noei, H.; Meyer, A.; Krekeler, T.; Jiao, C.; Stierle, A.; Abetz, V.; et al. Organically Linked Iron Oxide Nanoparticle Supercrystals with Exceptional Isotropic Mechanical Properties. Nat. Mater. 2016, 15 (5), 522-528.

(66) Chikazumi, S. Physics of Ferromagnetism, 2nd ed.; Oxford University Press: New York, 1999.

(67) Kodama, R.; Berkowitz, A.; McNiff, E.; Foner, S. Surface Spin Disorder in $\mathrm{NiFe}_{2} \mathrm{O}_{4}$ Nanoparticles. Phys. Rev. Lett. 1996, 77 (2), 394-397.

(68) Peddis, D.; Cannas, C.; Piccaluga, G.; Agostinelli, E.; Fiorani, D. Spin-Glass-like Freezing and Enhanced Magnetization in Ultra-Small $\mathrm{CoFe}_{2} \mathrm{O}_{4}$ Nanoparticles. Nanotechnology 2010, $21(12), 125705$.

(69) Coey, J. M. D. Magnetism and Magnetic Materials; Cambridge University Press, 2010.

(70) Pianciola, B. N.; Lima, E.; Troiani, H. E.; Nagamine, L. C. C. M.; Cohen, R.; Zysler, R. D. Size and Surface Effects in the Magnetic Order of $\mathrm{CoFe}_{2} \mathrm{O}_{4}$ Nanoparticles. J. Magn. Magn. Mater. 2015, 377, 44-51.

(71) Shenker, H. Magnetic Anisotropy of Cobalt Ferrite $\left(\mathrm{Co}_{1.01} \mathrm{Fe}_{2.00} \mathrm{O}_{3.62}\right)$ and Nickel Cobalt Ferrite $\left(\mathrm{Ni}_{0.72} \mathrm{Fe}_{0.20} \mathrm{Co}_{0.08} \mathrm{Fe}_{2} \mathrm{O}_{4}\right)$. Phys. Rev. 1957, 107 (5), 1246-1249.

(72) Mørup, S.; Hansen, M. F.; Frandsen, C. Magnetic Interactions between Nanoparticles. Beilstein J. Nanotechnol. 2010, 1, 182-190.

(73) De Toro, J. A.; Vasilakaki, M.; Lee, S. S.; Andersson, M. S.; Normile, P. S.; Yaacoub, N.; Murray, P.; Sánchez, E. H.; Muñiz, P.; Peddis, D.; et al. Remanence Plots as a Probe of Spin Disorder in Magnetic Nanoparticles. Chem. Mater. 2017, 29 (19), 8258-8268.

(74) Mazario, E.; Menéndez, N.; Herrasti, P.; Cañete, M.; Connord, V.; Carrey, J. Magnetic 
Hyperthermia Properties of Electrosynthesized Cobalt Ferrite Nanoparticles. J. Phys. Chem. C 2013, 117 (21), 11405-11411.

(75) Fantechi, E.; Innocenti, C.; Albino, M.; Lottini, E.; Sangregorio, C. Influence of Cobalt Doping on the Hyperthermic Efficiency of Magnetite Nanoparticles. J. Magn. Magn. Mater. 2015, 380, 365-371.

(76) Mameli, V.; Musinu, A.; Ardu, A.; Ennas, G.; Peddis, D.; Niznansky, D.; Sangregorio, C.; Innocenti, C.; Thanh, N. T. K.; Cannas, C. Studying the Effect of Zn-Substitution on the Magnetic and Hyperthermic Properties of Cobalt Ferrite Nanoparticles. Nanoscale 2016, 8 (19), 10124-10137.

(77) Rosensweig, R. E. Heating Magnetic Fluid with Alternating Magnetic Field. J. Magn. Magn. Mater. 2002, 252, 370-374.

Lima, E.; De Biasi, E.; Mansilla, M. V.; Saleta, M. E.; Granada, M.; Troiani, H. E.; Effenberger, F. B.; Rossi, L. M.; Rechenberg, H. R.; Zysler, R. D. Heat Generation in Agglomerated Ferrite Nanoparticles in an Alternating Magnetic Field. J. Phys. D. Appl. Phys. 2013, 46 (4), 45002.

(79) Carrey, J.; Mehdaoui, B.; Respaud, M. Simple Models for Dynamic Hysteresis Loop Calculations of Magnetic Single-Domain Nanoparticles: Application to Magnetic Hyperthermia Optimization. J. Appl. Phys. 2011, 109 (8), 83921.

(80) Ovejero, J. G.; Cabrera, D.; Carrey, J.; Valdivielso, T.; Salas, G.; Teran, F. J. Effects of Inter- and Intra-Aggregate Magnetic Dipolar Interactions on the Magnetic Heating Efficiency of Iron Oxide Nanoparticles. Phys. Chem. Chem. Phys. 2016, 18 (16), 1095410963.

(81) de Sousa, M. E.; Carrea, A.; Mendoza Zélis, P.; Muraca, D.; Mykhaylyk, O.; Sosa, Y. E.; 
Goya, R. G.; Sánchez, F. H.; Dewey, R. A.; Fernández van Raap, M. B. Stress-Induced Gene Expression Sensing Intracellular Heating Triggered by Magnetic Hyperthermia. J. Phys. Chem. C 2016, 120 (13), 7339-7348.

(82) Tan, R. P.; Carrey, J.; Respaud, M. Magnetic Hyperthermia Properties of Nanoparticles inside Lysosomes Using Kinetic Monte Carlo Simulations: Influence of Key Parameters and Dipolar Interactions, and Evidence for Strong Spatial Variation of Heating Power. Phys. Rev. B 2014, 90 (21), 214421.

(83) Martinez-Boubeta, C.; Simeonidis, K.; Serantes, D.; Conde-Leborán, I.; Kazakis, I.;

Stefanou, G.; Peña, L.; Galceran, R.; Balcells, L.; Monty, C.; et al. Adjustable Hyperthermia Response of Self-Assembled Ferromagnetic Fe-MgO Core-Shell Nanoparticles by Tuning Dipole-Dipole Interactions. Adv. Funct. Mater. 2012, 22 (17), 3737-3744.

(84) Winkler, E. L.; Lima, E.; Tobia, D.; Saleta, M. E.; Troiani, H. E.; Agostinelli, E.; Fiorani, D.; Zysler, R. D. Origin of Magnetic Anisotropy in $\mathrm{ZnO} / \mathrm{CoFe}_{2} \mathrm{O}_{4}$ and $\mathrm{CoO} / \mathrm{CoFe}_{2} \mathrm{O}_{4}$ Core/shell Nanoparticle Systems. Appl. Phys. Lett. 2012, 101 (25), 252405.

(85) Özgür, U.; Alivov, Y. I.; Liu, C.; Teke, a.; Reshchikov, M. a.; Doğan, S.; Avrutin, V.; Cho, S.-J.; Morkoç, H. A Comprehensive Review of ZnO Materials and Devices. J. Appl. Phys. 2005, $98(4), 41301$.

(86) Xiong, H.-M. Photoluminescent ZnO Nanoparticles Modified by Polymers. J. Mater. Chem. 2010, 20 (21), 4251-4262.

(87) Wood, A.; Giersig, M.; Hilgendorff, M.; Vilas-Campos, A.; Liz-Marzán, L. M.; Mulvaney, P. Size Effects in ZnO: The Cluster to Quantum Dot Transition. Aust. J. Chem. 2003, 56 (10), 1051-1057.

(88) Borgohain, C.; Senapati, K. K.; Sarma, K. C.; Phukan, P. A Facile Synthesis of 
Nanocrystalline $\mathrm{CoFe}_{2} \mathrm{O}_{4}$ Embedded One-Dimensional $\mathrm{ZnO}$ Hetero-Structure and Its Use in Photocatalysis. J. Mol. Catal. A Chem. 2012, 363-364, 495-500.

(89)

Sheetz, R. M.; Richter, E.; Andriotis, A. N.; Menon, M. Defect-Induced Optical Absorption in the Visible Range in ZnO Nanowires. Phys. Rev. B 2009, 80 (19), 195314.

(90) Schmidt-Mende, L.; MacManus-Driscoll, J. L. ZnO - Nanostructures, Defects, and Devices. Mater. Today 2007, 10 (5), 40-48.

(91) Fonoberov, V.; Alim, K.; Balandin, A.; Xiu, F.; Liu, J. Photoluminescence Investigation of the Carrier Recombination Processes in ZnO Quantum Dots and Nanocrystals. Phys. Rev. B 2006, $73(16), 165317$.

(92) Shalish, I.; Temkin, H.; Narayanamurti, V. Size-Dependent Surface Luminescence in ZnO Nanowires. Phys. Rev. B 2004, 69 (24), 245401.

(93) Inamdar, D. Y.; Pathak, A. K.; Dubenko, I.; Ali, N.; Mahamuni, S. Room Temperature Ferromagnetism and Photoluminescence of Fe Doped ZnO Nanocrystals. J. Phys. Chem. C 2011, 115 (48), 23671-23676.

(94) Zhang, W.; Zhao, J.; Liu, Z.; Liu, Z. Structural, Optical and Magnetic Properties of $\mathrm{Zn}_{1-\mathrm{x}} \mathrm{Fe}_{\mathrm{x}} \mathrm{O}$ Powders by Sol-gel Method. Appl. Surf. Sci. 2013, 284, 49-52. 
1

2

3

4

5

6

7

8

9

10

11

12

13

14

15

16

17

18

19

20

21

22

23

24

25

26

27

28

29

30

31

32

33

34

35

36

37

38

39

40

41

42

43

44

45

46

47

48

49

50

51

52

53

54

55

56

57

58

59

60

\section{TOC Graphic}

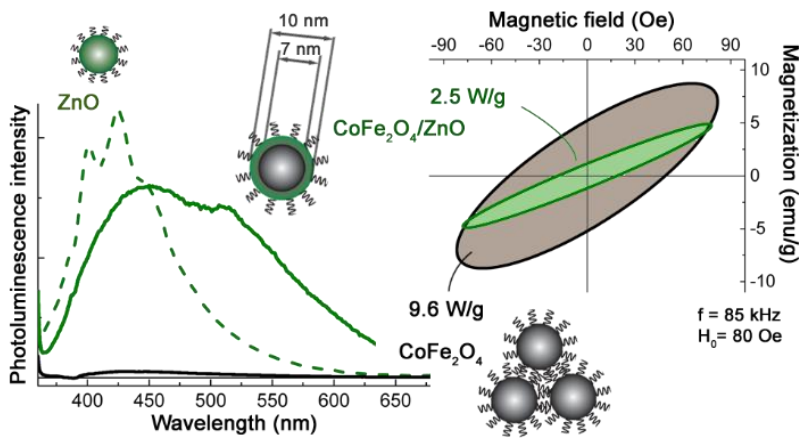

ACS Paragon Plus Environment 
